\title{
Changes of the glutathione redox system during the weaning transition in piglets, in relation to small intestinal morphology and barrier function
}

\author{
Jeroen Degroote ${ }^{1 *}$, Hans Vergauwen ${ }^{2}$, Wei Wang ${ }^{1}$, Chris Van Ginneken ${ }^{2}$, Stefaan De Smet ${ }^{1}$ and Joris Michiels ${ }^{1}$
}

\begin{abstract}
Background: Weaning is known to result in barrier dysfunction and villus atrophy in the immediate post-weaning phase, and the magnitude of these responses is hypothesized to correlate with changes in the glutathione (GSH) redox system. Therefore, these parameters were simultaneously measured throughout the weaning phase, in piglets differing in birth weight category and weaning age, as these pre-weaning factors are important determinants for the weaning transition. Low birth weight (LBW) and normal birth weight (NBW) littermates were assigned to one of three weaning treatments; i.e. weaning at 3 weeks of age $(3 w)$, weaning at 4 weeks of age $(4 w)$ and removal from the sow at $3 \mathrm{~d}$ of age and fed a milk replacer until weaning at 3 weeks of age (3d3w). For each of these treatments, six LBW and six NBW piglets were euthanized at $0,2,5,12$ or $28 \mathrm{~d}$ post-weaning piglets, adding up 180 piglets.
\end{abstract}

Results: Weaning increased the glutathione peroxidase activity on d 5 post-weaning in plasma, and duodenal and jejunal mucosa. Small intestinal glutathione-S-transferase activity gradually increased until d 12 post-weaning, and this was combined with a progressive rise of mucosal GSH up till d 12 post-weaning. Oxidation of the GSH redox status (GSH/GSSG $E_{h}$ ) was only observed in the small intestinal mucosa of $3 \mathrm{~d} 3 \mathrm{w}$ weaned piglets at $\mathrm{d} 5$ postweaning. These piglets also demonstrated increased fluorescein isothiocyanate dextran (FD4) and horseradish peroxidase fluxes in the duodenum and distal jejunum during the experiment, and specifically demonstrated increased FD4 fluxes at d 2 to d 5 post-weaning. On the other hand, profound villus atrophy was observed during the weaning transition for all weaning treatments. Finally, LBW and NBW piglets did not demonstrate notable differences in GSH redox status, small intestinal barrier function and histo-morphology throughout the experiment.

Conclusion: Although moderate changes in the GSH redox system were observed upon weaning, the GSH redox status remained at a steady state level in $3 w$ and $4 w$ weaned piglets and was therefore not associated with weaning induced villus atrophy. Conversely, 3d3w weaned piglets demonstrated GSH redox imbalance in the small intestinal mucosa, and this co-occurred with a temporal malfunction of their intestinal barrier function.

Keywords: Barrier function, Glutathione, Oxidative stress, Redox status, Small intestine, Weaned piglet

\footnotetext{
* Correspondence: jerdgroo.degroote@ugent.be

'Laboratory for Animal Nutrition and Animal Product Quality (LANUPRO),

Department of Animal Sciences and Aquatic Ecology, Faculty of Bioscience

Engineering, Ghent University, Block F, Campus Coupure, Coupure Links 653,

9000 Ghent, Belgium

Full list of author information is available at the end of the article
}

(c) The Author(s). 2020 Open Access This article is licensed under a Creative Commons Attribution 4.0 International License, which permits use, sharing, adaptation, distribution and reproduction in any medium or format, as long as you give appropriate credit to the original author(s) and the source, provide a link to the Creative Commons licence, and indicate if changes were made. The images or other third party material in this article are included in the article's Creative Commons licence, unless indicated otherwise in a credit line to the material. If material is not included in the article's Creative Commons licence and your intended use is not permitted by statutory regulation or exceeds the permitted use, you will need to obtain permission directly from the copyright holder. To view a copy of this licence, visit http://creativecommons.org/licenses/by/4.0/ The Creative Commons Public Domain Dedication waiver (http://creativecommons.org/publicdomain/zero/1.0/) applies to the data made available in this article, unless otherwise stated in a credit line to the data. 


\section{Background}

It is well known that abrupt weaning presents a challenge for the intestinal tract, as it needs to instantaneously adapt to sudden changes in feed intake, diet form and composition, nutrient digestibility and social and physical environment. Altogether, these changes induce stress [1], and potentially also induces inflammation and stimulation of the immune system [2]. As a result, weaning is associated with decreased gut health, most often documented by villus atrophy and impairment of the mucosal barrier function in especially the small intestine $[3,4]$. Hence, decreased animal performance, higher mortality and excessive use of antimicrobials are to date a major concern in pig production. Extensive research efforts have been made towards unraveling the mechanisms behind weaning induced alterations of gut health. The impact of age at weaning, gut maturation, the immediate post-weaning feed intake and social stress on digestive physiology, microbial and immunological processes are well documented [5-10] and together provide insight and opportunities for mitigation. Recent developments in redox biology might add to this and could particularly further elaborate on the relationship between the epithelial barrier function and villus atrophy. The concepts of redox biology extend beyond ordinary damage control (reactive oxygen species damage DNA, proteins and lipids and thereby affect cell functionality) in an event of oxidative stress. Importantly, redox biology also involves redox switches, e.g. redox sensitive cysteine residues in proteins, which enable fast post-translational modifications of proteins and thereby impact on their function [11]. These mechanisms offer a comprehensive view on tight junction regulation [12-15] and cell cycling from proliferation to apoptosis [16, 17], and hence link barrier function and cell turnover in the intestinal epithelium. Substantial evidence indicates the pivotal role of redox molecules such as glutathione (GSH). Together with its related enzymes, i.e. glutathione peroxidase (GPx) and glutathione-S-transferase (GST), the GSH redox system offers the opportunity to efficiently buffer undesirable oxidation reactions. When oxidized, GSH is converted to glutathione disulphide (GSSG), which is instantaneously reduced back to GSH by glutathione reductase. Cells tightly regulate these oxidation and reduction reactions and strive to keep GSH in a predominantly reduced status. By the law of Nernst, this status is expressed by its half-cell redox potential (GSH/ GSSG $E_{h}$ ) [18]. As this system is under catalytic control at multiple levels, disturbance of this steady state level is therefore considered to represent a thorough change in the redox environment of a tissue [18]. The fact that GSH not only functions as an indicator or buffer, but also actively partakes in the reversible formation of mixed disulfide through protein-S-glutathionylation, underlines the potential impact of these mechanisms in stressful events [11]. Although very fascinating, these complex insights, mainly generated in in vitro models, are not easily translated to in vivo research. Recent efforts however started to reveal the extent of weaning induced alterations of the antioxidant and redox system in vivo [19-27]. Nevertheless, it remains hard to formulate general patterns for antioxidant and redox biomarkers in relation to weaning. This is due to the vast amount of different biomarkers in use, the likelihood that reactions upon weaning are tissue specific [26], and the fact that numerous dietary and animal related factors influence the magnitude of weaning induced responses. The objective of this study was therefore to determine the responses of the antioxidant system upon weaning, with the focus on the small intestinal GSH redox system, in piglets that were subjected to different pre-weaning conditions. A vast body of literature namely documents how functional $[7,28,29]$ and also GSH redox [30-32] characteristics of the small intestine depend on birth weight and weaning age. Several authors report compromised digestive functions in suckling and fully weaned piglets that exhibit intrauterine growth restriction (IUGR) [28]. Some papers link this impaired gut health to alterations in the expression of redox-sensitive genes or proteins [30, 33]. Also weaning age, and particularly early weaning, repeatedly showed to impact on gut physiology [6, $29,34]$. In this respect, an earlier study demonstrated how artificial rearing of piglets, i.e. removal from the sow at $3 \mathrm{~d}$ of age and feeding a milk replacer, resulted in GSH redox imbalance and barrier disruption in the small intestine in the pre-weaning phase [31]. In the current study, we therefore aim to describe the post-weaning changes of the GSH redox system and explore the relations with the small intestinal integrity during the entire weaning transition in pigs with a low and normal birth weight that are subjected to different pre-weaning strategies.

\section{Methods}

\section{Experimental setup}

This experiment included 180 piglets (Piétrain $\times$ Topigs hybrid) selected during 5 consecutive farrowing rounds from 68 litters with 14 or more live born piglets. At the day of birth, 90 pairs of low birth weight (LBW) and normal birth weight (NBW) gender-matched littermates were selected based on criteria parallel to previous research [30, 31]. Piglets having a birth weight (BiW) between 0.75 and $0.90 \mathrm{~kg}$ and belonging to the lower quartile of their litter birth weight were classified as LBW, whereas an NBW littermate had a birth weight within $0.5 \mathrm{SD}$ units of the mean birth weight of the whole litter. Cross-fostered piglets were excluded for the study. Pairs of LBW and NBW littermates were assigned to one of three weaning treatments (WT); i.e. weaning at 3 weeks of age (19.6 $\pm 0.50 \mathrm{~d})$ $(3 w)$, weaning at 4 weeks of age $(26.6 \pm 0.50 \mathrm{~d})(4 \mathrm{w})$ and removal from the sow at $3 \mathrm{~d}$ of age and feeding a milk replacer until weaning at 3 weeks of age $(19.8 \pm 0.38 \mathrm{~d})$ $(3 \mathrm{~d} 3 \mathrm{w})$. These $3 \mathrm{~d} 3 \mathrm{w}$ weaned piglets were raised following 
the procedures described by De Vos et al. [35] and Vergauwen et al. [31], using a commercial brooder system (Rescue Deck ${ }^{\circ}$ ) where milk replacer was mixed with water at a ratio of $1 / 4(w / w)$, and was provided by an automated milk dispensing system. After weaning, piglets were housed in groups of 6 piglets per pen $(2.40 \mathrm{~m} \times 1.25 \mathrm{~m})$. Pens were equipped with a full slatted floor, drinker nipple and feeder trough. Piglets belonging to different birth weight and WT groups were housed in separate pens. All piglets were fed the same weaner diet ad libitum until sampling at either $0,2,5,12$ or $28 \mathrm{~d}$ post-weaning (DPW), where sampling a d 0 implicates transport to the lab and sampling within $6 \mathrm{~h}$ after maternal separation. Body weight was recorded at birth, weaning and sampling. Composition of the milk replacer and weaner diet can be found in annex (Additional file 1: Table S1). The experimental setup resulted in 30 different animal groups $(2 \times 3$ $\times 5$ factorial design; Biw, WT and DPW, respectively) with 6 piglets per group.

\section{Sample collection}

Piglets were sedated by electrical stunning and blood was collected during exsanguination in EDTA and heparin tubes containing supplemental bathophenanthroline disulfonate sodium salt. Subsequently, the gastrointestinal tract was dissected and the small intestine and liver were isolated. The length of the small intestine was measured. Both at 5\% (duodenum) and 75\% (distal jejunum) of the total length of the small intestine, three tissue samples, measuring $10 \mathrm{~cm}, 5 \mathrm{~cm}$ and $20 \mathrm{~cm}$, were taken, rinsed with a $0.9 \% \mathrm{NaCl}$-solution, and used in their respective order for Ussing chamber measurements, histomorphology, and collection of the mucosa by scraping the mucosal surface with a glass slide. Areas containing Peyer's patches were avoided.

\section{Oxidative and redox status}

Blood plasma was collected from EDTA tubes after centrifugation $(3,000 \times \mathrm{g}, 15 \mathrm{~min})$, and was stored at $-20^{\circ} \mathrm{C}$ until analysis of the oxygen radical absorbance capacity (ORAC), malondialdehyde (MDA) and GPx activity. ORAC was determined by the assay of $\mathrm{Ou}$ et al. [36]. The thiobarbituric acid reactive substances method [37] was used to quantify MDA as a marker for lipid peroxidation. GPx activity was determined spectrophotometrically by principles described by Hernandez et al. [38]. Erythrocytes were harvested by centrifuging $(3,000 \times \mathrm{g}, 15 \mathrm{~min}) 0.5 \mathrm{~mL}$ of heparinized blood, and removing the residual plasma. Erythrocytes were lysed with 70\% metaphosphoric acid solution and intense vortexing. An aliquot was transferred to a vial, containing $\gamma$-glutamyl-glutamate as an internal standard, and was snap frozen in liquid nitrogen before storing at $-80^{\circ} \mathrm{C}$. These samples were analyzed for GSH and GSSG. In addition, duodenal and jejunal tissue samples were slit longitudinally and mucosa was obtained by scraping off the surface with a glass slide. A sample was also taken central in the right lateral lobe of the liver. $\mathrm{Mu}$ cosal and liver samples were further treated according to the following procedure. A first tissue subsample was instantaneously turned into a phosphate buffered mucosal homogenate using $1 \%$ triton-X-100 phosphate buffer $(\mathrm{pH}$ $7.0,50 \mathrm{mmol} / \mathrm{L}$ ). An aliquot was taken to determine total protein content by the biuret method, before centrifuging the homogenate $\left(13,000 \times g, 15 \mathrm{~min}, 4^{\circ} \mathrm{C}\right)$. The supernatants was snap frozen and stored at $-80^{\circ} \mathrm{C}$ pending the analysis of GPx, MDA and GST. Here, GST was determined by measuring the increase in absorbance at $340 \mathrm{~nm}$ associated with the conjugation of GSH with 1-chloro-2,4dinitrobenzene catalyzed by GST [39]. A second subsample was instantaneously homogenized in a $10 \%$ perchloric acid solution. After centrifugation $(13,000 \times g, 15$ min, $4{ }^{\circ} \mathrm{C}$ ), the resulting acid extract was transferred to a tube containing a $\gamma$-glutamyl-glutamate internal standard solution. Samples were then snap frozen in liquid nitrogen and stored at $-80^{\circ} \mathrm{C}$. Later, GSH and GSSG concentrations were quantitated by high-performance liquid chromatography analysis [40, 41]. In brief, this method involves iodoacetic acid as a thiol quenching agent, 1-chloro-2,4-dinitrobenzene as derivatization reagent, reversed-phase HPLC separation on an aminopropyl column, and absorption measurement at $365 \mathrm{~nm}$. The GSH and GSSG concentrations were determined relative to internal and external standard solutions and were expressed on protein content. The GSH/GSSG $E_{h}$ value was calculated by using the appropriate forms of the Nernst equation, assuming a $\mathrm{pH}$ of 7.4 and a temperature of $37^{\circ} \mathrm{C}$ [18].

GSH/GSSG $\quad E_{h}(m V)=-264-61.5 / 2 \times \log _{10}\left(\mathrm{GSH}^{2} / \mathrm{G}\right.$ SSG).

\section{Histo-morphology}

Small intestinal samples were placed in $4 \%$ phosphate buffered formalin ( $\mathrm{pH} 7.4)$ for $2 \mathrm{~h}$ at room temperature. After rinsing with phosphate buffered saline, the tissue was dehydrated and paraffin embedded according to standard procedures. Transverse $5 \mu \mathrm{m}$ sections were stained with hematoxylin and eosin. Villus length, mid-villus width and crypt depth were assessed in 30 well oriented villi and adjacent crypts using image analysis software (Olympus BX 61, analySIS Pros, Aartselaar, Belgium).

\section{Ussing chamber macromolecular permeability}

The apparent permeability coefficients $\left(\mathrm{P}_{\text {app }}\right)$ of two macro-molecular markers; fluorescein isothiocyanate dextran $4 \mathrm{kDa}$ (FD4) and horseradish peroxidase $40 \mathrm{kDa}$ (HRP) was determined following experimental procedures described by Neirinckx et al. [42] and Michiels et al. [28]. Duodenal and jejunal segments were placed in oxygenated $\left(\mathrm{O}_{2} / \mathrm{CO}_{2}\right.$ 95/5) Ringer's buffer ( $\mathrm{pH} 7.4$, 
$115 \mathrm{mmol} / \mathrm{L} \mathrm{NaCl}, 5 \mathrm{mmol} / \mathrm{L} \mathrm{KCl}, 25 \mathrm{mmol} / \mathrm{L} \mathrm{NaHCO}$, $2.4 \mathrm{mmol} / \mathrm{L} \quad \mathrm{Na}_{2} \mathrm{HPO}_{4}, 1.25 \mathrm{mmol} / \mathrm{L} \quad \mathrm{CaCl}_{2}, 1 \mathrm{mmol} / \mathrm{L}$ $\mathrm{MgSO}_{4}$ ) solution at $38^{\circ} \mathrm{C}$ until processing and mounting within $10 \mathrm{~min}$ post-mortem. The mucosal and submucosal layer were stripped of its serosal and muscle layers, and the segments were opened longitudinally along the mesenteric border. At each intestinal site, two pieces of stripped tissue per piglet were mounted in Ussing chambers (Dipl.-ing Mußler Scientific Instruments, Aachen, Germany) with an exposed surface area of $1.07 \mathrm{~cm}^{2}$. Areas containing Peyer's patches were not exposed to the open surface area. Both mucosal and serosal compartments were simultaneously filled with $6.5 \mathrm{~mL}$ warm $\left(38^{\circ} \mathrm{C}\right)$ Ringer's buffer containing $6 \mathrm{mmol} / \mathrm{L}$ mannitol and glucose, respectively. The system was water-jacketed to $37^{\circ} \mathrm{C}$ and the buffer compartments were oxygenated with a $\mathrm{O}_{2} / \mathrm{CO}_{2}(95 / 5)$ gas flow. After an equilibration period of $20 \mathrm{~min}$, FD4 ( $4 \mathrm{kDa}$, Sigma-Aldrich, Bornem, Belgium) and HRP (40 kDa, type IV, Sigma-Aldrich, Bornem, Belgium) were added to the buffer compartment at the mucosal side to reach a final concentration of 0.8 $\mathrm{mg} / \mathrm{mL}$ FD4 and $0.4 \mathrm{mg} / \mathrm{mL}$ HRP. $200 \mu \mathrm{L}$ Samples were taken at the serosal buffer compartment at 20, 40, 60 and $80 \mathrm{~min}$ after adding the markers, whilst the same volume of buffer solution was taken from the mucosal buffer compartment to maintain volume balance across sides. Buffer compartments were wrapped in aluminum foil to provide light protection. $200 \mu \mathrm{L}$ Samples were stored at $-20^{\circ} \mathrm{C}$ in light resistant amber polypropylene copolymer vials until analysis. Fluorescence intensity of FD4 was measured at $\lambda_{\text {exc }}$ of $485 \mathrm{~nm}$ and $\lambda_{\text {em }}$ of $538 \mathrm{~nm}$ using a fluorescence plate reader (Thermo Scientific, Marietta, Ohio, USA). The HRP activity was measured by a modification of the Worthington method [43], following the rate of increase in optical density at $460 \mathrm{~nm}$ using a microplate absorbance reader (IMark, Bio-Rad, Hercules, California, USA). As in previous research [30, $31,44]$, the change in concentration of marker solution (dc/dt) in the acceptor compartment between 20 and $100 \mathrm{~min}$, the buffer volume in the donor compartment $(\mathrm{V})$, the initial marker concentration in the donor compartment $\left(\mathrm{C}_{0}\right)$, and the exposed tissue surface area $(\mathrm{A})$ were used to calculate the $\mathrm{P}_{\text {app }}$.

$$
\mathrm{P}_{\mathrm{app}}(\mathrm{cm} / \mathrm{s})=\mathrm{dc} / \mathrm{dt} \times \mathrm{V} /\left(\mathrm{A} \times \mathrm{C}_{0}\right) .
$$

\section{Small intestinal protein expression}

Similar to Vergauwen et al. [31], commercially available enzyme-linked immunosorbent assays (ELISA) of occludin $(\mathrm{SEC} 228 \mathrm{Hu})$, claudin-3 (SEF293Hu), proliferating cell nuclear antigen (PCNA) (SEA591Hu) and caspase-3 $(\mathrm{SEA626Hu})$ (Cloud-Clone Corporation ${ }^{\circ}$, Houston, TX, USA) were used to evaluate the protein concentration of specific tight junction proteins and markers for apoptosis and mitosis. In brief, mucosa scrapings that had been snap frozen in liquid nitrogen and stored at $-80^{\circ} \mathrm{C}$ were crushed in liquid nitrogen and lysed in a phosphate-buffered saline solution $(\mathrm{pH} 7.4,0.01 \mathrm{~mol} / \mathrm{L})$ by sonication. Subsequently, the samples were centrifuged $\left(10,000 \times g, 2 \mathrm{~min}, 4^{\circ} \mathrm{C}\right)$ and the supernatant was collected. Next, the total protein concentration was determined using a Pierce ${ }^{\mathrm{Tm}}$ bicinchoninic acid Assay (BCA) Kit (Thermo Scientific, Rockford, USA), and the supernatant was diluted to protein concentration of 10 $\mathrm{ng} / \mu \mathrm{L}$. Subsequently samples were processed following the manufacturer's guidelines. Absorbance was measured at $450 \mathrm{~nm}$ at $25^{\circ} \mathrm{C}$, and values of protein abundance were expressed as fmol per mg protein.

\section{Statistical analysis}

Data were analyzed using a general linear model procedure (IBM SPSS Statistics version 22). In all analyses, piglet served as the experimental unit. The model included the fixed effects of the three main factors, 1) birth weight (Biw), comparing LBW and NBW piglets, 2) weaning treatment (WT), comparing $3 \mathrm{~d} 3 \mathrm{w}, 3 \mathrm{w}$ and $4 \mathrm{w}$ weaned piglets and, 3 ) days post-weaning (DPW) comparing piglets of $0,2,5,12$ and $28 \mathrm{~d}$ post-weaning, and their two-way interaction terms. A post-hoc Tukey test was used to discriminate treatment differences for overall effects of the main study factors. If interaction terms reached $P \leq 0.10$, a second analysis was done where the effect of the first factor of the interaction term was tested for each experimental group of the second factor separately, and vice versa. Date are expressed as least squares means with their standard error (SE) in figures, or alternatively with the standard error of the grand mean (SEM) in tables. Differences were declared significant at $P \leq 0.05$.

\section{Results \\ Animal performance}

Several significant treatment effects and interactions on pre- and post-weaning performance were observed (Table 1). Selection on birth weight resulted in an LBW and an NBW group having a mean birth weight of respectively $0.85 \pm 0.09 \mathrm{~kg}$ and $1.37 \pm 18 \mathrm{~kg}$ (mean $\pm \mathrm{SD}$; $P<0.001)$. Pre-weaning average daily gain (ADG) was reduced by $29 \%$ in LBW piglets, resulting in a $31 \%$ lower average weaning weight. Besides Biw, also WT affected weaning weight. Due to the significant higher preweaning ADG $(+89 \mathrm{~g} / \mathrm{d})$ in $3 \mathrm{~d} 3 \mathrm{w}$ weaned piglets, this group exhibited a significantly higher weaning weight than piglets weaned at $3 \mathrm{w}(+1.77 \mathrm{~kg})$ and $4 \mathrm{w}$ of age $(+$ $0.43 \mathrm{~kg}$ ). Weaning weight was significantly higher in piglets weaned at $4 \mathrm{w}$ versus those weaned at $3 \mathrm{w}$ of age. This was however due to the difference in age, as preweaning ADG was not different between $3 \mathrm{w}$ and $4 \mathrm{w}$ weaned piglets. A significant interaction for WT $\times$ DPW 
Table 1 Body weights and growth performance of the piglets pre- and post-weaning

\begin{tabular}{|c|c|c|c|c|c|c|c|c|}
\hline & $\begin{array}{l}\text { Animals, } \\
n\end{array}$ & $\begin{array}{l}\text { Birth } \\
\text { weight, } \mathrm{kg}\end{array}$ & $\begin{array}{l}\text { Weaning } \\
\text { weight, } \mathrm{kg}\end{array}$ & $\begin{array}{l}\text { Final } \\
\text { weight, } \mathrm{kg}\end{array}$ & $\begin{array}{l}\text { ADG pre- } \\
\text { weaning, g/d }\end{array}$ & $\begin{array}{l}\text { ADG post- } \\
\text { weaning, } \mathrm{g} / \mathrm{d}\end{array}$ & $\begin{array}{l}\text { ADFl post- } \\
\text { weaning, g/d }\end{array}$ & $\begin{array}{l}\text { FCR post-weaning } \\
\text { (ADG/ ADFI) }\end{array}$ \\
\hline \multicolumn{9}{|c|}{ Birth weight category (Biw) } \\
\hline LBW & 90 & 0.85 & 4.95 & 6.64 & 189 & 30 & 145 & 0.21 \\
\hline NBW & 90 & 1.37 & 7.14 & 9.27 & 266 & 43 & 183 & 0.23 \\
\hline \multicolumn{9}{|c|}{ Weaning treatment (WT) } \\
\hline $3 d 3 w$ & 60 & 1.10 & $6.78^{c}$ & $8.68^{b}$ & $287^{b}$ & $-6^{a}$ & $182^{b}$ & -0.03 \\
\hline $3 w$ & 60 & 1.12 & $5.01^{\mathrm{a}}$ & $6.70^{\mathrm{a}}$ & $198^{\mathrm{a}}$ & $40^{b}$ & $140^{\mathrm{a}}$ & 0.29 \\
\hline $4 w$ & 60 & 1.11 & $6.35^{b}$ & $8.49^{b}$ & $197^{a}$ & $75^{c}$ & $168^{\mathrm{b}}$ & 0.45 \\
\hline \multicolumn{9}{|c|}{ Day post-weaning (DPW) } \\
\hline d 0 & 36 & 1.09 & 5.98 & $5.98^{x}$ & 227 & - & - & - \\
\hline $\mathrm{d} 2$ & 36 & 1.09 & 5.88 & $5.47^{x}$ & 223 & $-203^{w}$ & $44^{w}$ & $-4.61^{y}$ \\
\hline d 5 & 36 & 1.14 & 6.20 & $6.01^{x}$ & 233 & $-37^{x}$ & $107^{x}$ & $-0.35^{y z}$ \\
\hline d 12 & 36 & 1.16 & 6.13 & $7.46^{y}$ & 230 & $113^{y}$ & $222^{y}$ & $0.51^{y z}$ \\
\hline d 28 & 36 & 1.08 & 6.03 & $14.86^{z}$ & 226 & $309^{z}$ & $444^{z}$ & $0.70^{z}$ \\
\hline SEM & - & 0.01 & 0.07 & 0.10 & 3 & 5 & 3 & 0.34 \\
\hline \multicolumn{9}{|l|}{$P$-value } \\
\hline BiW & & $<0.001$ & $<0.001$ & $<0.001$ & $<0.001$ & 0.163 & & \\
\hline WT & & 0.842 & $<0.001$ & $<0.001$ & $<0.001$ & $<0.001$ & & \\
\hline DPW & & 0.089 & 0.634 & $<0.001$ & 0.876 & $<0.001$ & & \\
\hline $\mathrm{BiW} \times \mathrm{L}$ & $P W$ & 0.321 & 0.990 & 0.012 & 0.960 & 0.005 & & \\
\hline$W T \times D$ & PW & 0.472 & 0.033 & 0.037 & 0.074 & $<0.001$ & & \\
\hline$B i W \times 1$ & & 0.989 & 0.864 & 0.863 & 0.101 & 0.560 & & \\
\hline
\end{tabular}

Birth weight (BiW), weaning treatment (WT), days post-weaning (DPW), Average daily gain (ADG), average daily feed intake (ADFI), feed conversion ratio (FCR). Piglets were either weaned at 3 weeks of age $(3 \mathrm{w}), 4$ weeks of age $(4 \mathrm{w})$, or separated from the sow at $3 \mathrm{~d}$ of age and fed a milk replacer until weaning at $3 \mathrm{w}$ of age $\left(3 \mathrm{~d} 3 \mathrm{w}\right.$ ), and either had a low birth weight or normal birth weight (NBW). ${ }^{\mathrm{a}, \mathrm{b}, \mathrm{c}}$ Within column, means without a common superscript differ for the effect of weaning treatment (WT: $P \leq 0.05$ ). ${ }^{w, x y, z}$ Within column, means without a common superscript differ for the effect of days post-weaning (DPW: $\left.P \leq 0.05\right)$.

was observed regarding the weaning weight $(P=0.033)$. Apparently, at random allocation did not result in a perfect representation of the overall effect of WT for piglets sampled on different days post-weaning. Nevertheless, stratification for weaning weight across the different days post-weaning was successful within a weaning treatment (Additional file 2: Table S3), and no interaction terms reached significance regarding the preweaning ADG (Table 1).

After weaning, Biw, WT and DPW all significantly influenced body weight at sampling. On average, significant body weight loss was observed at d 2 post-weaning, and piglets caught up with their initial weight on $\mathrm{d} 5$ post-weaning (DPW: $P<0.001$ ). This post-weaning growth check was however larger in $3 \mathrm{~d} 3 \mathrm{w}$ weaned piglets, as $3 \mathrm{~d} 3 \mathrm{w}$ weaned piglets exhibited lower ADG ($379 \mathrm{~g} / \mathrm{d})$ compared to $3 \mathrm{w}(-134 \mathrm{~g} / \mathrm{d})$ and $4 \mathrm{w}(-96 \mathrm{~g} / \mathrm{d})$ weaned piglets (WT $\times$ DPW: $P<0.001$ ) on $\mathrm{d} 2$ postweaning. A similar effect was seen on d 5 post-weaning, where ADG was still significantly lower in $3 \mathrm{~d} 3 \mathrm{w}$ versus $4 \mathrm{w}$ weaned piglets. Nevertheless, $3 \mathrm{~d} 3 \mathrm{w}$ weaned piglets reached a significantly higher body weight at d 28 post- weaning compared to $3 \mathrm{w}$ and $4 \mathrm{w}$ weaned piglets (Additional file 2: Table S4). Next, although Biw did not significantly impact post-weaning ADG $(P=0.163)$, the effect of Biw was found to depend on the day postweaning $(\mathrm{BW} \times \mathrm{DPW}: P=0.005)$. LBW piglets sampled at 2 or $5 \mathrm{~d}$ post-weaning did not differ in ADG from NBW piglets $(P<0.05)$ (Additional file 2: Table S3) but they started to have a reduced ADG when kept until 12 or $28 \mathrm{~d}$ post-weaning $(P \leq 0.05)$.

\section{The oxidative status and glutathione redox system}

The total antioxidant capacity of plasma was assessed by means of the ORAC assay (Table 2). The ORAC values significantly dropped from d 2 to $\mathrm{d} 12$ and d 28 postweaning (DPW: $P<0.001$ ) and were lower in $3 \mathrm{~d} 3 \mathrm{w}$ weaned piglets compared to $4 \mathrm{w}$ weaned piglets $(P<$ 0.001). Concentrations of MDA (Table 2), a marker for lipid peroxidation, were affected by DPW $(P<0.001)$. Plasma levels were lower on d 5 and d 12 compared with $\mathrm{d} 0$ and $\mathrm{d} 28$ post-weaning. In the duodenal mucosa and liver tissue, MDA concentrations were significantly increased on $\mathrm{d} 28$ versus $\mathrm{d} 0$ post-weaning, opposite to 
Table 2 Effect of birth weight $(n=90)$, weaning treatment $(n=60)$ and days post-weaning $(n=36)$, and their interaction $(n=12-30)$, on oxidative stress biomarkers in weaned piglets

\begin{tabular}{|c|c|c|c|c|c|c|c|c|c|c|c|c|c|c|c|c|c|}
\hline & \multicolumn{2}{|c|}{$\begin{array}{l}\text { Birth weight } \\
\text { (Biw) }\end{array}$} & \multicolumn{3}{|c|}{$\begin{array}{l}\text { Weaning treatment } \\
\text { (WT) }\end{array}$} & \multicolumn{5}{|c|}{ Days post-weaning (DPW) } & \multirow[t]{2}{*}{ SEM } & \multicolumn{6}{|c|}{$P$-value } \\
\hline & LBW & NBW & $3 d 3 w$ & $3 w$ & $4 w$ & $\mathrm{~d} 0$ & $\mathrm{~d} 2$ & d5 & $\mathrm{d} 12$ & $\mathrm{~d} 28$ & & $\mathrm{BiW}$ & WT & DPW & $\mathrm{BiW} \times \mathrm{DPW}$ & WT $\times$ DPW & $\mathrm{BiW} \times \mathrm{WT}$ \\
\hline \multicolumn{18}{|c|}{ ORAC, $\mu$ mol trolox eq. $/ \mathrm{mL}$} \\
\hline PLA & 23.4 & 23.5 & $22.6^{\mathrm{a}}$ & $24.4^{\mathrm{b}}$ & $23.3^{\mathrm{ab}}$ & $24.1^{y}$ & $24.6^{2}$ & $24.2^{y z}$ & $22.7^{x y}$ & $21.7^{\times}$ & 0.2 & 0.901 & $<0.001$ & $<0.001$ & 0.536 & 0.252 & 0.640 \\
\hline \multicolumn{18}{|c|}{ MDA, nmol/mg prot. } \\
\hline PLA* & 10.9 & 10.7 & 11.1 & 10.9 & 10.5 & $11.6^{z}$ & $11.0^{\mathrm{yz}}$ & $10.2^{y}$ & $10.0^{y}$ & $11.3^{z}$ & 0.1 & 0.386 & 0.127 & $<0.001$ & 0.713 & 0.661 & 0.306 \\
\hline DUO & 299 & 285 & 288 & 304 & 284 & $261^{y}$ & $283^{y}$ & $287^{y z}$ & $296^{y z}$ & $332^{z}$ & 6 & 0.210 & 0.337 & $<0.001$ & 0.972 & 0.040 & 0.782 \\
\hline JEJ & 334 & 351 & $312^{\mathrm{a}}$ & $371^{b}$ & $343^{\mathrm{ab}}$ & $408^{z}$ & $416^{z}$ & $282^{y}$ & $296^{y}$ & $310^{y}$ & 8 & 0.301 & 0.016 & $<0.001$ & 0.788 & $<0.001$ & 0.402 \\
\hline LIV & 634 & 650 & 648 & 640 & 637 & $646^{y}$ & $504^{x}$ & $632^{y}$ & $675^{y z}$ & $754^{z}$ & 12 & 0.502 & 0.926 & $<0.001$ & 0.825 & 0.005 & 0.343 \\
\hline
\end{tabular}

Birth weight (Biw), weaning treatment (WT), day post-weaning (DPW), oxygen radical scavenging activity (ORAC), malondialdehyde (MDA), blood plasma (PLA), duodenal mucosa (DUO), distal jejunal mucosa (JEJ), liver tissue (LIV). Piglets were either weaned at three weeks of age (3w), four weeks of age (4w), or separated from the sow at $3 \mathrm{~d}$ of age and fed a milk replacer until weaning at $3 \mathrm{w}$ of age $(3 \mathrm{~d} 3 \mathrm{w})$, and either had a low birth weight or normal birth weight (NBW). a,b Within a row, means without a common superscript differ for the effect of weaning treatment (WT: $P \leq 0.05)$. ${ }^{x, y, z}$ Within a row, means without a common superscript differ for the effect of days post-weaning (DPW: $P \leq 0.05$ ). ${ }^{*}$ Expressed in $\mathrm{nmol} / \mathrm{mL}$ plasma

what was found in the distal jejunal mucosa where values were higher on $\mathrm{d} 0$ and $\mathrm{d} 2$ versus $\mathrm{d} 5, \mathrm{~d} 12$ and d 28 post-weaning (DPW: $P<0.001$ ). Distal jejunal MDA levels were also found to be significantly higher in $4 \mathrm{w}$ versus $3 \mathrm{~d} 3 \mathrm{w}$ weaned piglets (WT: $P=0.016$ ). Nevertheless, when comparing different weaning treatments, moderate variations in the overall effect of DPW on MDA levels were observed (WT $\times$ DPW: $P<0.05$ ).

During the weaning transition, GSH levels were affected in erythrocytes $(P<0.001)$, the duodenal mucosa $(P<$ $0.001)$ and the distal jejunal mucosa $(P=0.053)$. On average, GSH concentrations were found to increase significantly towards the end of the weaning transition (d 12 or d 28 post-weaning). Nevertheless, this general pattern was influenced by weaning treatment in erythrocyte and jejunal mucosal (WT $\times$ DPN: $P \leq 0.05$ ). In erythrocytes, the GSH increase was not observed in $3 \mathrm{~d} 3 \mathrm{w}$ weaned piglets. Consequently, erythrocyte GSH levels at d 12 and d 28 post-weaning were significantly lower in $3 \mathrm{~d} 3 \mathrm{w}$ weaned piglets when comparing with $3 \mathrm{w}$ and $4 \mathrm{w}$ weaned piglets. In the distal jejunum, GSH levels were significantly lower in $3 \mathrm{~d} 3 \mathrm{w}$ weaned piglets at $\mathrm{d} 2$ and $\mathrm{d} 5$ post-weaning, compared to the age-matched $3 \mathrm{w}$ weaned piglets (Additional file 2: Table S4). These differences are also reflected in the average GSH level per weaning treatment, where $3 \mathrm{~d} 3 \mathrm{w}$ weaned piglets showed the lowest GSH levels in erythrocytes, the duodenal and distal jejunal mucosa (WT: $P \leq$ 0.05). Remarkably, average GSSG levels were increased in the small intestinal mucosa of $3 \mathrm{~d} 3 \mathrm{w}$ weaned piglets (WT: $P=0.05)$ and GSSG levels were significantly influenced by DPW $(P \leq 0.05)$, as observed for GSH. In general, GSSG levels were highest at $\mathrm{d} 28$ post-weaning in the duodenal mucosa, but in the distal jejunal mucosa, GSSG levels were highest at $d 5$ post-weaning. Yet again, the effect of DPW on mucosal GSSG levels was influenced by the weaning treatment (WT $\times$ DPW: $P<0.001)$. Most importantly, GSSG concentrations in the small intestinal mucosa were increased on d 5 post-weaning in $3 \mathrm{~d} 3 \mathrm{w}$ weaned piglets, when compared to $3 \mathrm{w}$ and $4 \mathrm{w}$ weaned piglets $(P \leq 0.001)$ (Additional file 2: Table S4). To evaluate the changes in GSSG relative to the changes in GSH levels, the GSH/GSSG $E_{h}$ gives a comprehensive view of the redox status of the GSH pool. Here, a higher value, i.e. closer to zero, indicates a more oxidized redox status, which can be attributed to increased GSSG and/or reduced GSH levels. Results indicate that GSH/GSSG $E_{h}$ values remain relatively stable in erythrocytes and the distal jejunal mucosa during the weaning transition (DPW: $P>0.05)$. DPW effects were only found in the duodenal mucosa and liver, where a significantly more oxidized GSH pool was observed at $\mathrm{d} 28$ versus $\mathrm{d} 12$ post-weaning. Besides, hepatic GSH redox status was significantly lower at d 5 post-weaning (Additional file 2: Table S2). Importantly, these general patterns were found to differ between different weaning treatments (WT $\times$ DPW: $P \leq 0.05$ ). These differences are depicted in Fig. 1 and can be found in Table S4 (Additional file 2). It was remarkable that both in the duodenal and distal jejunal mucosa, the GSH/GSSG $\mathrm{E}_{\mathrm{h}}$ of $3 \mathrm{~d} 3 \mathrm{w}$ weaned piglets indicated significantly more oxidation on $\mathrm{d} 5$ post-weaning when compared with weaning at $3 \mathrm{w}$ and $4 \mathrm{w}$ of age. In contrast, the GSH/GSSG $\mathrm{E}_{\mathrm{h}}$ was in a more reduced state in the distal jejunal mucosa at $\mathrm{d} 2$ post-weaning in $3 \mathrm{w}$ weaned piglets, compared to $3 \mathrm{~d} 3 \mathrm{w}$ and $4 \mathrm{w}$ weaned piglets. Secondly, the increase in GSH/GSSG $E_{h}$ at $d 28$ that was observed in duodenal and liver tissue was only seen in $4 \mathrm{w}$ and $3 \mathrm{w}$ weaned piglets. Next, with regard to erythrocytes, $4 \mathrm{w}$ weaned piglets were characterized by a more reduced GSH redox pool on d 0 and $d 28$ post-weaning. Finally, in accordance with what was observed for GSH and GSSG, the GSH/GSSG $\mathrm{E}_{\mathrm{h}}$ indicates a more oxidized GSH redox pool in erythrocytes and small intestinal mucosa in $3 \mathrm{~d} 3 \mathrm{w}$ versus $4 \mathrm{w}$ weaned piglets, 


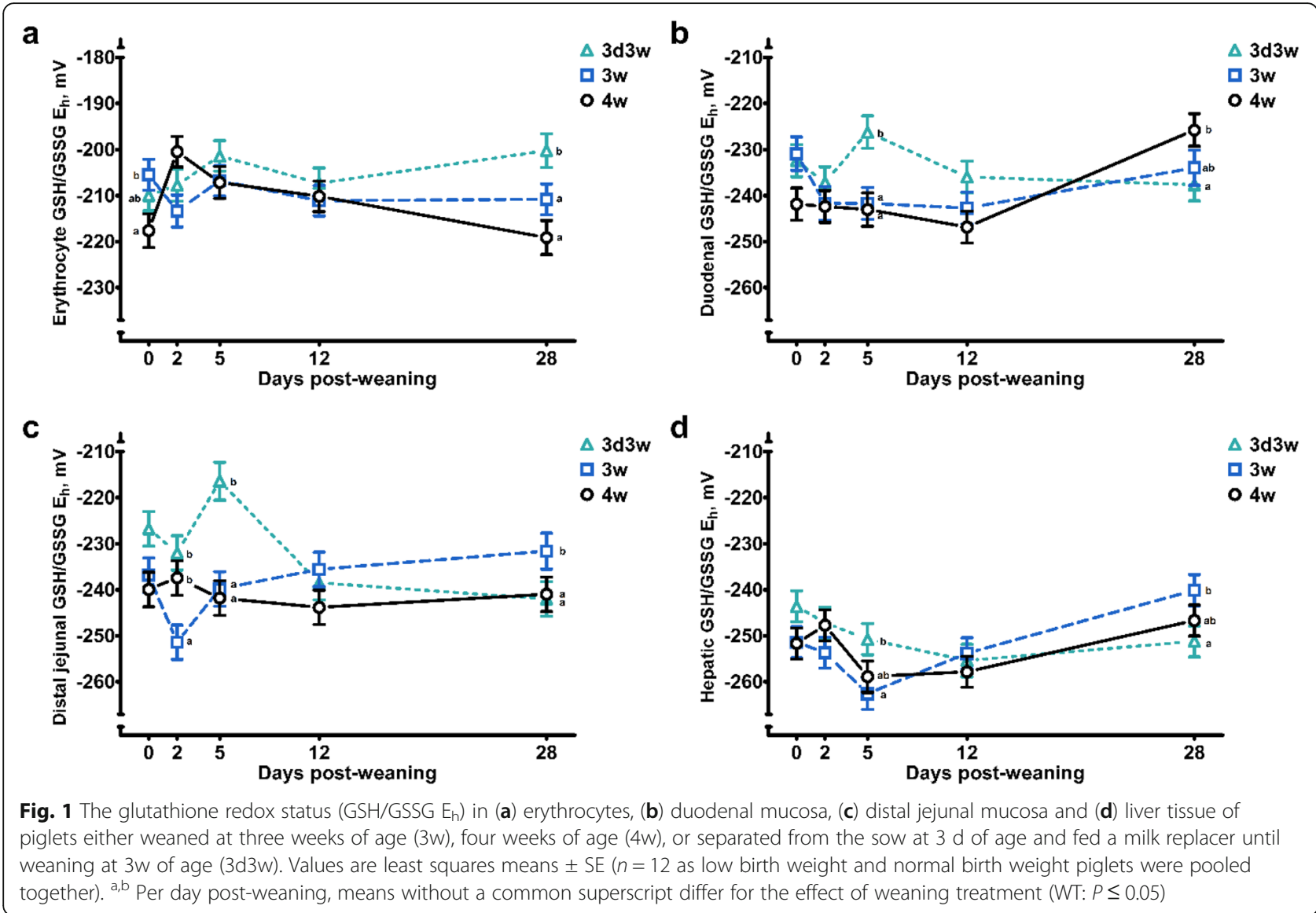

irrespective of the day post-weaning (WT: $P<0.05)$ (Additional file 2: Table S2).

Concerning the GSH related enzymes, the weaning transition was found to be the most determining factor, as DPW significantly influenced GPx and GST activities in all measured tissues (Table 3). GPx activity peaked on d 5 post-weaning in plasma and small intestinal mucosa. In liver tissue however, this pattern was different, as GPx activities temporarily declined on d 2 post-weaning. Small but significant effects were also found for WT and the interaction term WT $\times$ DPW, where $3 \mathrm{~d} 3 \mathrm{w}$ weaned piglets were characterized by a higher hepatic GPx activity, particularly on d 12 post-weaning, comparing with 4w weaned piglets (Additional file 2: Tables S2 and Table S4). The GST activity was found to peak on d 12 in the distal jejunum. In the duodenum, values were high at $\mathrm{d} 12$ and $\mathrm{d} 28$ post weaning, whereas in the liver, the activity was highest on $\mathrm{d} 28$ post-weaning. Hepatic GST activity was lower in $3 \mathrm{w}$ versus in $4 \mathrm{w}$ weaned piglets (WT: $P=0.010$ ), and this decrease was also observed for these piglets in the small intestinal mucosa at specific days post-weaning (Additional file 2: Table S4) (WT $\times$ DPW: $P<0.05)$. Finally, a significant effect of Biw on the GSH redox system was observed. Here, the Biw $\times$ WT term indicated a significant effect for the duodenal GST activity. Still, post-hoc analysis could not further differentiate treatment groups here. Hence no noteworthy observations can be reported. This leads to the conclusion that DPW and WT had a high impact on the GSH redox system, and no evidence was found differentiating LBW and NBW piglets.

\section{Small intestinal histo-morphology and mitotic/apoptotic protein expression}

Figure 2 illustrates the most important treatment effects on the duodenal and distal jejunal histo-morphology. Overall findings are available in Table S2 (Additional file 2). Generally, weaning was followed by shortening of the villi in the duodenum on $\mathrm{d} 2$ post-weaning, and gradual recovery up to the original length and widening of the villi on $\mathrm{d} 28$ post-weaning. Crypt depth also increased upon weaning (DPW: $P<0.001$ ), and crypts reached their maximum depth on $d 12$ post-weaning. These patterns were however somewhat different for $3 \mathrm{~d} 3 \mathrm{w}$ weaned piglets (Additional file 2: Table S4). Villus width and crypt depth were significantly higher in the duodenum on $\mathrm{d} 0$ and $\mathrm{d} 2$ post-weaning, when compared to $3 \mathrm{w}$ and $4 \mathrm{w}$ weaned piglets. In the distal jejunum, post-weaning changes to histo-morphological indices were more outspoken, as villus atrophy persisted until d 5 post- 
Table 3 Effect of birth weight $(n=90)$, weaning treatment $(n=60)$ and days post-weaning $(n=36)$, and their interaction $(n=12-30)$, on the glutathione redox system in weaned piglets

\begin{tabular}{|c|c|c|c|c|c|c|c|c|c|c|c|c|c|c|c|}
\hline & \multicolumn{4}{|c|}{$\mathrm{GSH}, \mu \mathrm{mol} / \mathrm{mg}$ prot. } & \multicolumn{4}{|c|}{ GSSG, $\mu \mathrm{mol} / \mathrm{mg}$ prot. } & \multicolumn{4}{|c|}{ GPx, U/g prot. } & \multicolumn{3}{|c|}{ GST, U/g prot. } \\
\hline & $\overline{E R Y^{\S}}$ & DUO & JEJ & LIV & $\overline{E R Y^{\S}}$ & DUO & JEJ & LIV & $\overline{\mathrm{PLA}^{\dagger}}$ & DUO & JEJ & LIV & $\overline{\mathrm{DUO}}$ & JEJ & LIV \\
\hline \multicolumn{16}{|c|}{ Birth weight category (BiW) } \\
\hline LBW & 955 & 22 & 15.6 & 46.9 & 60 & 0.71 & 0.35 & 0.85 & 0.286 & 8.9 & 8.6 & 31.8 & 28.1 & 10.9 & 78 \\
\hline NBW & 989 & 21.9 & 16.1 & 43.6 & 65 & 0.72 & 0.38 & 0.8 & 0.292 & 8.7 & 8.7 & 31.8 & 29.6 & 10.4 & 76.6 \\
\hline \multicolumn{16}{|c|}{ Weaning treatment (WT) } \\
\hline $3 d 3 w$ & $893^{\mathrm{a}}$ & $20.6^{a}$ & $14.5^{\mathrm{a}}$ & 40.6 & 69 & $0.83^{b}$ & $0.44^{\mathrm{b}}$ & 0.8 & 0.279 & $8.2^{\mathrm{a}}$ & 9.5 & $33.7^{\mathrm{b}}$ & 28.7 & 10.4 & $73.6^{\mathrm{ab}}$ \\
\hline $3 w$ & $1010^{\mathrm{b}}$ & $22.1^{\mathrm{ab}}$ & $16.9^{b}$ & 44 & 62 & $0.64^{\mathrm{a}}$ & $0.36^{\mathrm{ab}}$ & 0.78 & 0.285 & $9.6^{b}$ & 8.1 & $31.4^{\mathrm{ab}}$ & 27.9 & 10.8 & $69.7^{\mathrm{a}}$ \\
\hline $4 w$ & $1012^{\mathrm{b}}$ & $23.2^{\mathrm{b}}$ & $16.2^{\mathrm{ab}}$ & 51.2 & 56 & $0.68^{\mathrm{ab}}$ & $0.30^{\mathrm{a}}$ & 0.9 & 0.302 & $8.6^{\mathrm{ab}}$ & 8.4 & $30.3^{\mathrm{a}}$ & 29.9 & 10.7 & $88.6^{\mathrm{b}}$ \\
\hline \multicolumn{16}{|c|}{ Day post-weaning (DPW) } \\
\hline d 0 & $938^{y}$ & $17.8^{x}$ & $14.4^{y}$ & 51.3 & 56 & $0.55^{x y}$ & $0.35^{y z}$ & $0.89^{y z}$ & $0.235^{x}$ & $8.2^{y z}$ & $7.1^{y}$ & $33.4^{z}$ & $22.3^{y}$ & $10.7^{\mathrm{yz}}$ & $81.5^{y z}$ \\
\hline $\mathrm{d} 2$ & $881^{y}$ & $17.6^{x}$ & $15.8^{y z}$ & 39.9 & 57 & $0.38^{x}$ & $0.26^{y}$ & $0.73^{y}$ & $0.280^{x y}$ & $9.9^{z}$ & $9.7^{2}$ & $28.0^{y}$ & $20.5^{y}$ & $10.2^{y z}$ & $56.0^{x}$ \\
\hline d 5 & $842^{y}$ & $22.1^{y}$ & $16.3^{y z}$ & 44.4 & 67 & $0.74^{y}$ & $0.48^{z}$ & $0.61^{y}$ & $0.373^{z}$ & $9.9^{z}$ & $10.6^{z}$ & $32.1^{\mathrm{yz}}$ & $26.5^{y}$ & $8.2^{y}$ & $67.9^{x y}$ \\
\hline d 12 & $997^{y}$ & $27.3^{z}$ & $18.1^{z}$ & 50.1 & 60 & $0.75^{y}$ & $0.41^{\mathrm{yz}}$ & $0.73^{y}$ & $0.304^{y}$ & $8.7^{y z}$ & $9.8^{z}$ & $33.2^{z}$ & $37.1^{z}$ & $12.5^{z}$ & $78.4^{x y}$ \\
\hline d 28 & $1201^{z}$ & $25.0^{x y}$ & $14.0^{y z}$ & 40.7 & 73 & $1.17^{z}$ & $0.32^{y z}$ & $1.17^{z}$ & $0.253^{x}$ & $7.3^{y}$ & $6.3^{y}$ & $32.4^{y z}$ & $37.9^{z}$ & $11.6^{y z}$ & $102.8^{z}$ \\
\hline SEM & 21 & 0.4 & 0.4 & 2.4 & 2 & 0.03 & 0.02 & 0.05 & 0.005 & 0.2 & 0.3 & 0.5 & 1.1 & 0.4 & 2.7 \\
\hline \multicolumn{16}{|l|}{$P$-value } \\
\hline BiW & 0.416 & 0.850 & 0.616 & 0.499 & 0.353 & 0.882 & 0.502 & 0.565 & 0.615 & 0.758 & 0.892 & 0.998 & 0.474 & 0.544 & 0.798 \\
\hline WT & 0.033 & 0.027 & 0.054 & 0.195 & 0.072 & 0.051 & 0.054 & 0.478 & 0.195 & 0.018 & 0.121 & 0.032 & 0.736 & 0.939 & 0.010 \\
\hline DPW & $<0.001$ & $<0.001$ & 0.053 & 0.450 & 0.085 & $<0.001$ & 0.029 & 0.002 & $<0.001$ & $<0.001$ & $<0.001$ & 0.009 & $<0.001$ & 0.013 & $<0.001$ \\
\hline BiW $\times$ DPW & 0.687 & 0.682 & 0.416 & 0.211 & 0.983 & 0.200 & 0.796 & 0.891 & 0.807 & 0.525 & 0.344 & 0.645 & 0.475 & 0.580 & 0.887 \\
\hline WTXDPW & $<0.001$ & 0.067 & 0.026 & 0.276 & 0.143 & $<0.001$ & $<0.001$ & 0.001 & 0.040 & 0.325 & 0.738 & 0.049 & 0.039 & 0.012 & 0.874 \\
\hline $\mathrm{BiW} \times \mathrm{WT}$ & 0.493 & 0.123 & 0.391 & 0.654 & 0.906 & 0.423 & 0.999 & 0.966 & 0.676 & 0.523 & 0.896 & 0.310 & 0.043 & 0.763 & 0.930 \\
\hline
\end{tabular}

Birth weight (BiW), weaning treatment (WT), days post-weaning (DPW), glutathione (GSH), glutathione disulphide (GSSG), glutathione peroxidase (GPx), glutathione transferase (GST), duodenal mucosa (DUO), distal jejunal mucosa (JE)), liver tissue (LIV). Piglets were either weaned at 3 weeks of age (3w), 4 weeks of age (4w), or separated from the sow at $3 \mathrm{~d}$ of age and fed a milk replacer until weaning at $3 \mathrm{w}$ of age (3d3w), and either had a low birth weight or normal birth weight (NBW). Values are least squares means. ${ }^{a, b}$ Within a column, means without a common superscript differ for the effect of weaning treatment (WT: $\left.P \leq 0.05\right)$. $x, y, z$ Within a column, means without a common superscript differ for the effect of days post-weaning (DPW: $P \leq 0.05)$. ${ }^{\S}$ Expressed in $\mathrm{nmol} / \mathrm{mL}$ blood. $†$ Expressed in U/mL blood plasma

weaning, and villi were still $114 \mu \mathrm{m}$ shorter on $\mathrm{d} 28$ as compared to $\mathrm{d} 0$ post-weaning. Villus length was also found to be higher in $3 \mathrm{w}$ weaned piglets compared to $3 \mathrm{~d} 3 \mathrm{w}$ and $4 \mathrm{w}$ weaned piglets (WT: $P=0.002$ ), and this was attributed to significantly higher values on $\mathrm{d} 2$ and d 28 post-weaning (WT $\times$ DPW: $P=0.010$ ). Widening of the jejunal villi took place up till $\mathrm{d} 28$ post-weaning (DPW: $P<0.001$ ), and an increased villi width was found in $3 \mathrm{~d} 3 \mathrm{w}$ weaned piglets on $\mathrm{d} 0$ and $\mathrm{d} 2$ postweaning (WT $\times$ DPW: $P=0.007)$. Distal jejunal crypts reached their maximum size at $d 12$ post-weaning and were on average deeper in $3 \mathrm{~d} 3 \mathrm{w}$ compared to $3 \mathrm{w}$ weaned piglets (WT: $P=0.001$ ). The factor Biw did not significantly affect these three histo-morphology parameters and did not interact with WT or DPW.

Concerning the PCNA and caspase-3 protein expression (Fig. 3), effects were limited to the main study factors (Additional file 2: Table S2). The PCNA expression was affected in the distal jejunal mucosa, where values were lower on $\mathrm{d} 5$ versus $\mathrm{d} 2$ post-weaning (DPW: $P=$
0.029). Caspase-3 was also significanlty reduced on $d 5$, when compared with d 0 post-weaning (DPW: $P=$ 0.010 ). Average caspase- 3 expression was lower in $3 \mathrm{~d} 3 \mathrm{w}$ weaned piglets, when comparing with $3 \mathrm{w}$ weaned piglets (WT: $P=0.052$ ). Birth weight did not affect the presence of these proteins in the small intestinal mucosa $(P>$ $0.05)$.

\section{Small intestinal barrier function and tight junction protein expression}

Ex vivo macromolecular permeability was determined in the duodenum and distal jejunal mucosa and was found to be significantly affected throughout the weaning transition (DPW) and in some cases by weaning treatment (Additional file 2: Table S2). The FD4 permeability was increased at $\mathrm{d} 2$ versus $\mathrm{d} 28$ post-weaning in the duodenum (DPW: $P=0.013$ ), and at $\mathrm{d} 2$ versus $\mathrm{d} 0$ post-weaning in the distal jejunum (DPW: $P=0.017$ ). Moreover, average FD4 permeability was higher in $3 \mathrm{~d} 3 \mathrm{w}$ weaned piglets (WT: $P \leq 0.05)$. Nevertheless, the interaction of WT $\times$ 

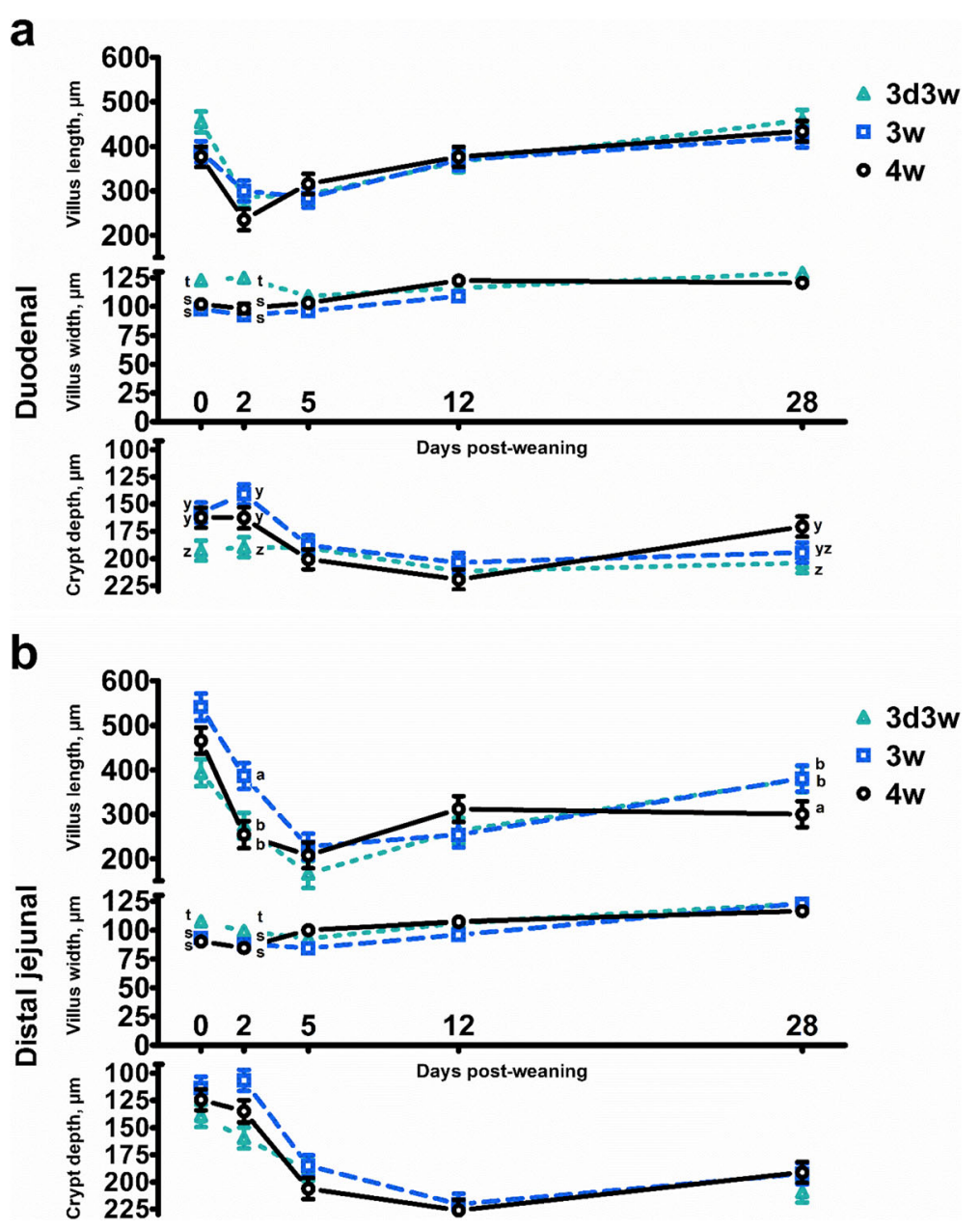

Fig. 2 Villus length, villus width and crypt depth (a) in the duodenum and (b) distal jejunum of piglets either weaned at three weeks of age ( $3 w$ ), four weeks of age ( $4 \mathrm{w}$ ), or separated from the sow at $3 \mathrm{~d}$ of age and fed a milk replacer until weaning at $3 \mathrm{w}$ of age ( $3 \mathrm{~d} 3 \mathrm{w}$ ). Values are least squares means \pm SE ( $n=12$ as low birth weight and normal birth weight piglets were pooled together). ${ }^{a, b}$ Per day post-weaning, means for villus length without a common superscript differ for the effect of weaning treatment (WT: $P \leq 0.05)$. s,t Per day post-weaning, means for villus width without a common superscript differ for the effect of weaning treatment (WT: $P \leq 0.05)$. ${ }^{y, z}$ Per day post-weaning, means for crypt depth without a common superscript differ for the effect of weaning treatment (WT: $P \leq 0.05$ )

DPW tended to influence these patterns $(P<0.10)$ (Fig. 4) (Additional file 2: Table S4). In the duodenum, FD4 flux was significantly higher on $\mathrm{d} 5$ post-weaning in $3 \mathrm{~d} 3 \mathrm{w}$ versus $3 \mathrm{w}$ and $4 \mathrm{w}$ weaned piglets. This was in accordance with FD4 fluxes in the distal jejunum, where major increases were found on $\mathrm{d} 2, \mathrm{~d} 5$ and $\mathrm{d} 12$ postweaning in $3 \mathrm{~d} 3 \mathrm{w}$ weaned piglets, when comparing to both $3 \mathrm{w}$ and $4 \mathrm{w}$ weaned piglets. Permeability was also affected by DPW in 3w weaned piglets, where the FD4 flux on d 2 post-weaning was significantly increased compared to $4 \mathrm{w}$ weaned piglets. At both intestinal sites, the FD4 flux was not affected by DPW in $4 \mathrm{w}$ weaned piglets. Contrasting to FD4, the HRP fluxes were not significantly altered the first $5 \mathrm{~d}$ postweaning. In the duodenum however, a significant decline was observed on d 12 and d 28 post-weaning, when comparing with $\mathrm{d} 0$ and $\mathrm{d} 5$ post-weaning. Extraordinarily, again $3 \mathrm{~d} 3 \mathrm{w}$ weaned piglets showed the highest HRP permeability compared to $3 \mathrm{w}$ and $4 \mathrm{w}$ weaned piglets. No interaction terms reached significance levels, and neither did Biw influence FD4 or HRP permeability.

Figure 5 illustrates the expression of two tightjunction proteins, occludin and claudin-3, in the small intestinal mucosa. Here, DPW only affected the occludin expression in the distal jejunal mucosa, as expression was significantly reduced on $\mathrm{d} 5$ versus d 2 post-weaning (Additional file 2: Table S2). Besides, $3 \mathrm{~d} 3 \mathrm{w}$ weaned piglets were characterized by a higer expression of occludin in the distal jejunum 

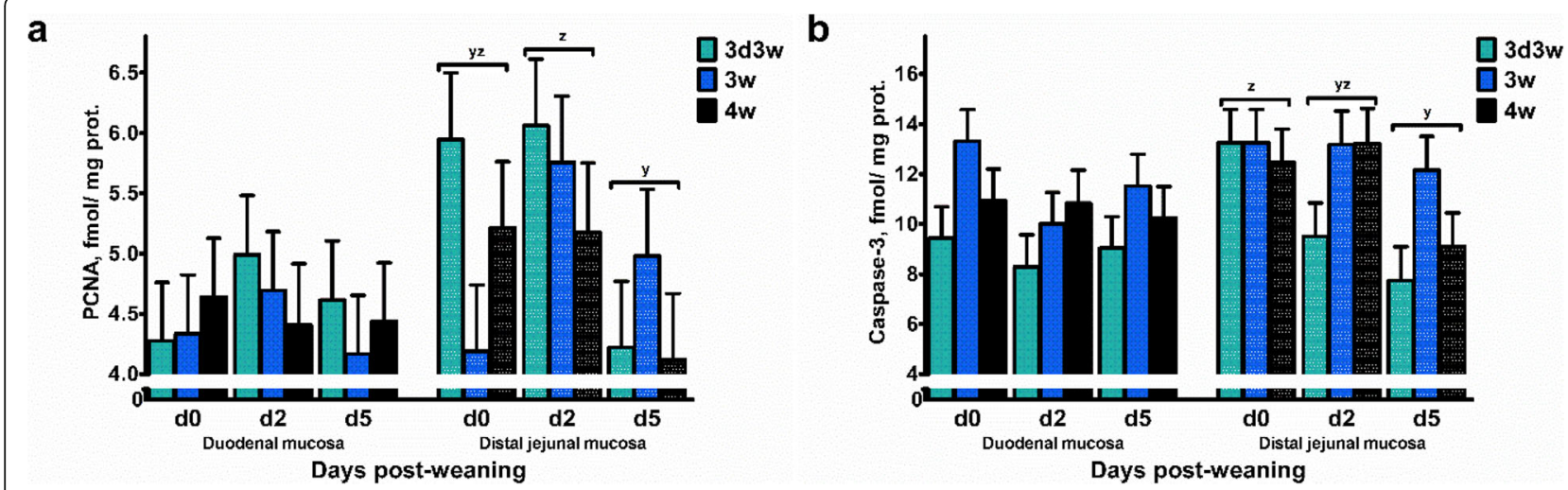

Fig. 3 Protein expression of (a) proliferating cell nuclear antigen (PCNA) and (b) caspase-3 in the duodenal and distal jejunal mucosa of piglets either weaned at 3 weeks of age (3w), 4 weeks of age (4w), or separated from the sow at $3 \mathrm{~d}$ of age and fed a milk replacer until weaning at $3 \mathrm{w}$ of age (3d3w). Values are least squares means + SE ( $n=12$ as low birth weight and normal birth weight piglets were pooled together). ${ }^{y, z}$ Means without a common superscript differ for the effect of days post-weaning (DPW: $P \leq 0.05$ )

compared to $4 \mathrm{w}$ weaned piglets, and a higher claudin-3 expression at both the duodenum and jejunum compared to $3 \mathrm{w}$ weaned pigelts $(P \leq 0.05)$ (Additional file 2: Table S2). Finally, Biw and all interaction terms did not reach significance levels.

\section{Discussion}

Weaning treatment but not birth weight defines weaning induced alterations of the glutathione redox system

From the results on animal performance, it appears that the experimental setup indeed resulted in groups of

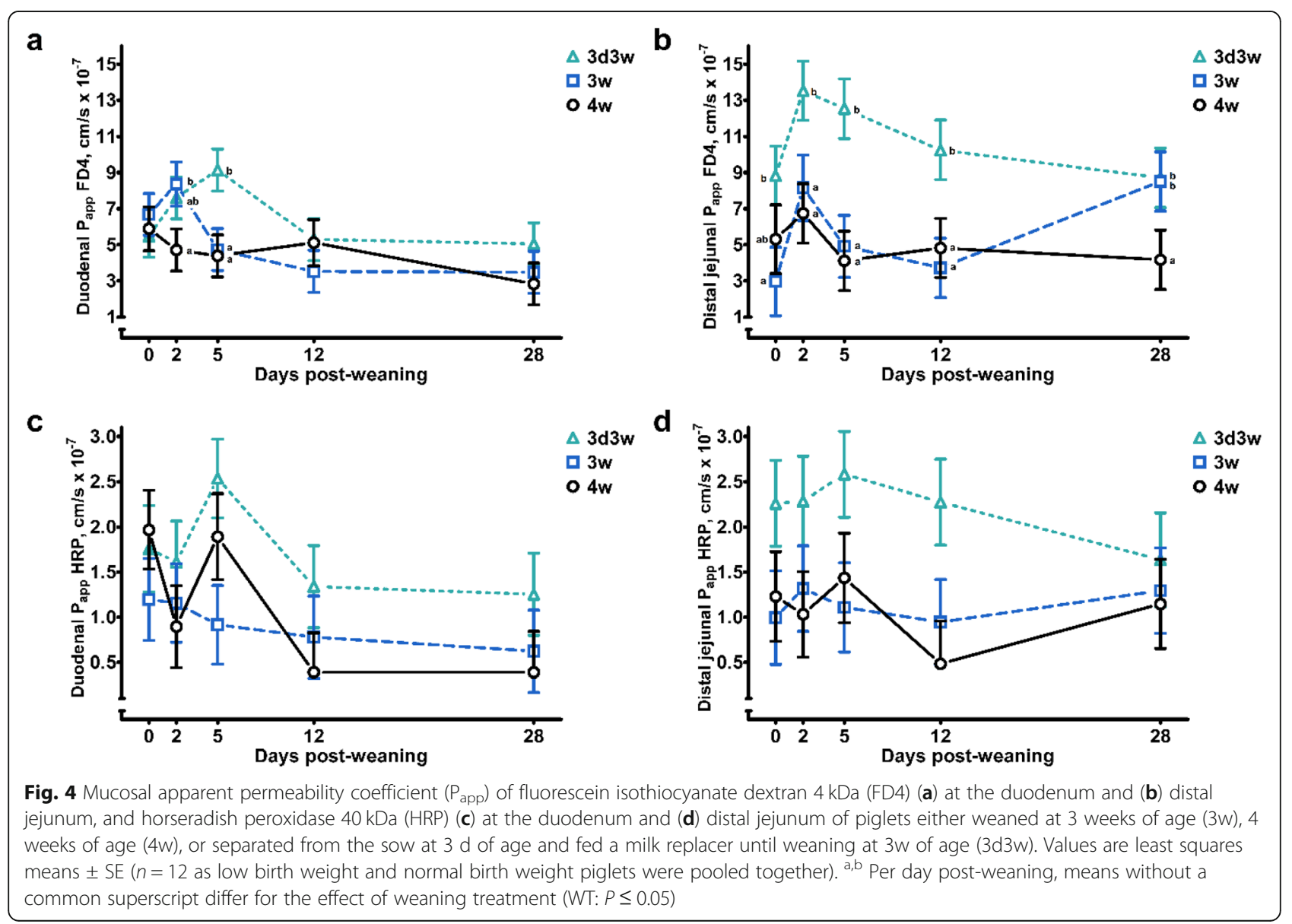



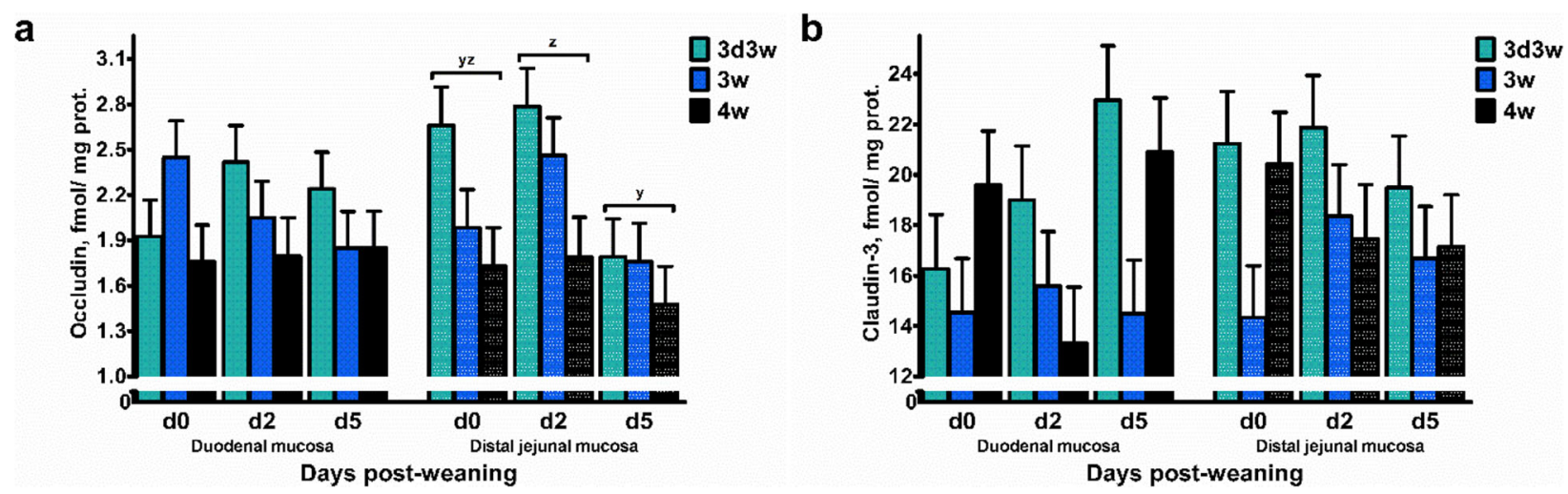

Fig. 5 Protein expression of (a) occludin and (b) claudin-3 in the duodenal and distal jejunal mucosa of piglets either weaned at 3 weeks of age $(3 \mathrm{w}), 4$ weeks of age $(4 \mathrm{w})$, or separated from the sow at $3 \mathrm{~d}$ of age and fed a milk replacer until weaning at $3 \mathrm{w}$ of age (3d3w). Values are least squares means \pm SE ( $n=12$ as low birth weight and normal birth weight piglets were pooled together). ${ }^{y, z}$ Means without a common superscript differ for the effect of days post-weaning (DPW: $P \leq 0.05$ )

piglets that were already quite different at the start of the weaning transition, and in consequence they experienced the weaning transition in a different way. For example, $3 \mathrm{~d} 3 \mathrm{w}$ weaned piglets experienced markedly more weight loss in the immediate post-weaning period ( $\mathrm{d} 2$ and $\mathrm{d} 5$ post-weaning), while on the other hand having a low birth weight resulted in a reduced post-weaning ADG when approaching the end of the weaning transition (d 12 to $\mathrm{d} 28$ post-weaning). Nevertheless, as weaning attenuated performance in all animal groups, it is likely that overall patterns on the oxidative status and GSH redox system can be deduced. And indeed, the weaning transition affected the majority of biomarkers that were analyzed, signaling that changes of the antioxidant system do occur during the weaning transition. Nevertheless, these markers did not coherently point into the direction of severe oxidative stress. For example, MDA changes in the duodenum were reverse to the distal jejunum where a gradual increase and decrease were observed, respectively. A decline in duodenal and distal jejunal MDA was also observed in an earlier study [19]. Even more, hepatic MDA was reduced on d 2 postweaning. In agreement with Degroote et al. [19, 44], plasma MDA levels were lower on d 5 and d 12 postweaning. Yet studies comparing weaned piglets with age-matched unweaned controls do report increased MDA levels in serum [23, 45, 46], intestinal mucosa [24, 25 ] and liver [22] in the first week after weaning. In line with no indication for lipid peroxidation being increased at weaning, the total antioxidant capacity in plasma, assessed by ORAC, was not affected in the immediate post-weaning phase. The antioxidant potential was rather reduced when approaching the end of the weaning transition. These observations seem to correlate to our earlier observations at similar time points [44], whereas other studies reported either unaffected [46, 47] or decreased [22, 24, 25, 45, 48] total antioxidant capacities in the first 2 weeks post-weaning. Yet, interesting evidence is provided by measurements of the GPx activity, as this was clearly increased in plasma and intestinal mucosa on d5-post-weaning. This illustrates a higher requirement for reducing power at that time, and correlates with other studies describing a similar event in plasma [19, 20], small intestinal mucosa $[19,21]$ and liver [22]. In contrast, hepatic GPx activity was transiently reduced after weaning in the current study, and some authors also report a decreased activity in serum [23] or intestinal mucosa $[24,25]$ when comparing to age-matched unweaned controls. Next, also the mucosal GST activity gradually increased until d 12 postweaning, and this was accompanied with a progressive rise of mucosal GSH till d 12 post-weaning, as observed before [19]. As both GSH and GST are required to increase the intestinal conjugation of electrophiles, e.g. lipid hydroperoxides, mycotoxins, etc., their simultaneous increase empowers this function in the small intestine of weaned piglets [49]. It is curious however to not have observed a transient decline in tissue GSH levels upon weaning. This was for example observed in studies of Degroote et al. [26], Li et al., [21] and Robert et al. [20] although admitting these studies only covered two to three time points in the first 2 weeks upon weaning. Altogether, these above-mentioned changes illustrate that the GSH system takes action to prevent oxidative stress and to conserve redox homeostasis, thereby facilitating normal cellular functions [11, 17]. A more complete evaluation of the activity, cellular and subcellular distribution of GSH-related enzymes and other oxidoreductases is however required to assess how these changes facilitate normal cell functions in the gut epithelium [50-53]. In the current study, the distal jejunal GSH redox status was not affected by weaning. In the 
duodenum, more oxidation was found on d 28 versus d 12 post-weaning. Nevertheless, in most cases the GSH redox status amounted to -230 to $-240 \mathrm{mV}$, which corresponds to a fairly reduced steady state redox environment in the mucosa $[17,54]$. Nevertheless, one major event of redox disturbance in the small intestine was observed, that was on $\mathrm{d} 5$ post-weaning in $3 \mathrm{~d} 3 \mathrm{w}$ weaned piglets. Interestingly, this was caused by oxidation of GSH to GSSG, as GSH levels were not lower than on preceding days. This form of redox disturbance was also found by Degroote et al. [19], although others also described weaning induced GSH depletion [20], and both GSH depletion and oxidation [21, 27]. Nevertheless, intestinal GSH levels on d 5 in 3d3w weaned animals were lower when comparing with other weaning treatments. The low levels persisted in these animals throughout the weaning transition. Thus, piglets separated from the sow and fed a milk replacer until weaning exhibited a different GSH redox response upon weaning compared to piglets that remained with the sow. The cause for this can be partially related to the fact that these animals experienced a very abrupt form of weaning, i.e. being weaned from ad libitum access to a milk replacer without pre-weaning access to a creep feed. Body weight loss upon weaning was consequently highest in these animals. Maternal separation at a very young age is also known to affect gut functionality and inflict GSH redox imbalance already in the pre-weaning phase [31]. Finally, in sharp contrast to weaning treatment, the factor birth weight did not display major effects in this trial. Therefore, although several studies describe a decreased antioxidant capacity of LBW piglets in the pre-weaning stage $[30,33]$ or when fully weaned $[28,32]$, no evidence was found here to support a differential GSH redox response upon weaning.

\section{Small intestinal villus atrophy during the weaning transition was not related to disturbance of the mucosal glutathione redox status}

As expected, weaning was followed by villus atrophy, widening of the villi and deepening of the crypts in the small intestine $[29,55]$. It is widely accepted that these developments represent increased cellular proliferation in the crypt, and apoptosis and sloughing at the villus tip [56-58]. In the current study however, mitotic and apoptotic indices, assessed by the protein expression of PCNA and caspase-3, respectively, did not illustrate this phenomenon. For example, the protein expression of PCNA and caspase3 were not altered in duodenum during the first $5 \mathrm{~d}$ postweaning. Besides, the distal jejunal protein expression for these two central components in the mitotic and apoptotic response were decreased on $\mathrm{d} 5$ post-weaning. Here, an increased protein expression was rather expected $[22,59]$. Nevertheless, based on the major histo-morphological adaptations, it is plausible that weaning resulted in substantial alterations of the epithelial cell turnover [10]. Connected to this, recent advances in redox biology suggest that important cell cycle signaling pathways are under regulation of redox active thiols such as GSH. These mechanisms have been comprehensively reviewed by Circu and Aw [17, 54] and Jones [16], and for example define how a cellular GSH/GSSG $E_{h}$ of over $-220 \mathrm{mV}$ is believed to inhibit cell proliferation. Values of over $-180 \mathrm{mV}$ can activate pro-apoptotic signaling, while values over $-150 \mathrm{mV}$ can result in necrosis. In the current study, where the GSH/GSSG $E_{h}$ was determined in simple mucosal scrapings, this association was not found in vivo during the weaning transition. In $3 \mathrm{w}$ and $4 \mathrm{w}$ weaned piglets for example, the mucosal GSH redox status was found to remain at its steady state level of approximately $-240 \mathrm{mV}$, although massive changes in histo-morphology occurred during the course. Even more, although $3 \mathrm{~d} 3 \mathrm{w}$ weaned piglets demonstrated a GSH redox imbalance at d 5 postweaning, amounting to approximately $-220 \mathrm{mV}$ in both the duodenal and distal jejunal mucosa, no critical differences in villus and crypt architecture were observed compared to other weaning treatments at that time point. This aligns with an important study of Tian et al. [60], where $D$, $L$-buthionine-sulfoximine as a specific inhibitor of GSH synthesis was applied in the ileum of rats. This technique inflicted severe mucosal GSH redox imbalance, without provoking changes in histo-morphological indices. Still, we did observe a somewhat dissimilar histo-morphological structure of the small intestine in $3 \mathrm{~d} 3 \mathrm{w}$ weaned piglets in the current study, but these differences were found to occur already at $\mathrm{d} 0$ and $\mathrm{d} 2$ post-weaning. They are rather believed to result from adaptation to pre-weaning conditions. Deeper crypts and wider villi were for instance found in the pre-weaning period by Vergauwen et al. [31] and De Vos et al. [35].

\section{Abrupt weaning was associated with barrier disruption, and this co-occurred with redox imbalance}

In general, it can be stated that barrier disruption occurred in the small intestine upon weaning in this experiment. Paracellular permeability, assessed by the FD4 flux $(4 \mathrm{kDa})$, peaked on $\mathrm{d} 2$ to $\mathrm{d} 5$ post-weaning in piglets that were artificially reared up till weaning. This substantiates our earlier findings where both transient and long-lasting effects, respectively in the duodenum and the distal jejunum, were observed on the FD4 flux after maternal separation [31]. It should however be noted that the composition of the milk replacer could have impacted on the effect of artificial rearing. For example, Boudry et al. [61] showed that both the protein content and polyunsaturated fatty acids levels [62] could potentially determine the outcome on barrier function. In the current study, the composition of the milk 
replacer was identical to our previous study [31], and resembles a protein level $(249 \mathrm{~g} / \mathrm{kg}$ crude protein or $50 \mathrm{~g} / \mathrm{L}$ milk) similar to the low protein diet in Boudry et al. [61]. Vegetable oils in the current milk replacer formula originated from coconut and accordingly are low in polyunsaturated fatty acids. Furthermore, the duodenal FD4 flux was also affected at $\mathrm{d} 2$ post-weaning in piglets that were conventionally raised until $3 \mathrm{w}$ of age. Boudry et al. [55] and $\mathrm{Hu}$ et al. [63] made similar observations at more distal intestinal sites, in piglets that were weaned at $21 \mathrm{~d}$ of age. In contrast, studies that weaned piglets at four to even 7 weeks of age rather report unaltered FD4 fluxes at the mid-small intestine $[6,8]$. Indeed, significant work of Smith et al. [7] revealed how weaning age, through stress-induced mast cell degranulation, can impact on the mucosal barrier in the intestine. Altogether, this evidence further confirms that, as observed in this study, weaning age can be an important trigger in post-weaning barrier disruption. To further support our results, the tight junction protein expression of occludin and claudin-3 were assessed in mucosal samples until $\mathrm{d} 5$ post-weaning. These two transmembrane proteins, enabling cell-cell adhesions at the apical side of the intestinal epithelium, play an important role in the regulation of the transcellular barrier [64]. Occludins primary regulate transmembrane transport of uncharged molecules, while claudins control paracellular ion transport [65]. From the claudin family, claudin-3 was analyzed because it also influences paracellular transport of uncharged solutes like FD4 [66]. Bearing in mind the large difference in paracellular permeability between different weaning treatments and the fact that their protein abundance was affected in the pre-weaning period [31], is was hypothesized that these measurements would elaborate more on the functionality of the mucosal barrier $[9,63]$. This was however not the case, as average distal jejunal occludin levels were highest in $3 \mathrm{~d} 3 \mathrm{w}$ weaned piglets and were not affected in the duodenal mucosa. Although weaning treatment did not influence the claudin-3 levels at given day post-weaning, average claudin-3 protein expression was highest in $3 \mathrm{~d} 3 \mathrm{w}$ weaned piglets. This is similar to or previous study [31], were small intestinal claudin-3 levels were twofold higher in artificially reared versus sow reared piglets at weaning age, although claudin-3 levels were decrease in cooccurrence with barrier dysfunction at maternal separation. Importantly, the FD4 flux only yields the permeability of the whole tissue and not that of its individual components [67], and its interpretations is further complicated by variations in junctional density and the absorptive surface area [68]. Second, not only the absolute tight junction protein quantity but also its phosphorylation status and consequently its distribution can be responsible for the treatment response on FD4 flux [12, 64].
Although this was not assessed in the current study, some observations suggest that this could be the case in the current study, particularly for $3 \mathrm{~d} 3 \mathrm{w}$ weaned piglets. These animals demonstrated lower GSH stores and a more oxidized GSH redox status in the small intestine throughout the experiment, and particularly demonstrated redox imbalance on $\mathrm{d} 5$ post-weaning. Importantly, oxidative stress is known to affect barrier function through several mechanisms [13, 15], for example by oxidization of redox sensitive protein tyrosine phosphatases (PTPs), which in turn induce phosphorylation and cellular redistribution of tight junction complexes [12]. This would thus imply that redox disturbance and barrier dysfunction have a common cause, being reactive oxygen species that directly induce oxidation of GSH and tight junction regulation proteins. Secondly, protein glutathionylation pathways can directly link the GSH redox system to tight junction functionality. Glutathionylation of specific cysteine residues in mitogen-activated protein kinases (MAPK) [69-71] and PTPs [12, 27, 72] affect their transduction and regulatory properties and ultimately lead to an altered tight junction functionality. Both GSH depletion and GSSG accumulation seem to be crucial events in this mechanism [13, 73]. Here, redox changes in target proteins, initiated by reactive oxygen species or GSH redox imbalance, often precede protein glutathionylation and affects the binding strength of GSH to a protein [74, 75]. Although a close cause-and-effect relationship between redox imbalance and barrier disruption cannot be deduced from the current study, Lou et al. [22] demonstrates that weaning altered MAPK phosphorylation patterns in the liver of piglets, and this cooccurred with oxidative stress. The GSH redox status was however not quantified in that study. Finally, the permeability and size selectivity of the paracellular route in the small intestine potentially also depends on the mucosal surface area accessible to the marker probe. The transepithelial flux of uncharged solutes through crypt tight junctions is far more permeable than in the villous [76-78]. Crypt hyperplasia is therefore likely to contribute to the paracellular the FD4 flux [79]. In the current study, we observed weaning-induced crypt hyperplasia for all weaning treatments. Artificial rearing did not affect crypt depth in the distal jejunum as compared to other weaning treatments, although FD4 permeability was most affected at this site by the $3 \mathrm{~d} 3 \mathrm{w}$ weaning treatment. Hence, we assume that other factor should account for the observations on paracellular permeability.

The transepithelial HRP flux was employed as measure for transcellular permeability, as intact proteins like HRP are assumed to cross the epithelium 
mainly via transcytosis $[3,80-84]$. Results show that the HRP permeability was not increased in the course of the first $5 \mathrm{~d}$ post-weaning. This correlates to research of Spreeuwenberg et al. [8], where also paracellular but not transcellular permeability in the midsmall intestine was increased upon weaning. Indeed, the current study even shows a decrease in HRP permeability when approaching the end of the weaning transition. This was only significantly observed in the duodenum at d 12 and $\mathrm{d} 28$ post weaning, but was already earlier observed by Boudry et al. [55] in the jejunal and ileal mucosa. Most remarkably, postweaning HRP fluxes were increased in piglets that were artificially reared until weaning at $3 \mathrm{w}$ of age. This could correlate to the transient increase in HRP flux that we previously observed shortly after maternal separation [31]. This long-lasting modification of barrier function, most clearly observed in the distal jejunum, draws attention to a risk for more antigen uptake across the intestinal epithelium in these animals. A decrease in HRP flux, normally observed upon weaning $[4,55]$ and partially confirmed in the current study, is considered to represent an enhancement of the gut maturation process. This is suggested to protect the animal from excessive antigen uptake and activation of the immune system [3]. In important note however is that, in case of severe mucosal damage, HRP can also undergo paracellular transport due to complete loss of tight junction $[79,82,83$, 85]. As long lasting increases of both FD4 and HRP fluxes were observed in the distal jejunum of artificially reared piglets, this observation could signal unrestricted paracellular transport and thus a complete loss of tight junction functionality [79].

\section{Conclusions}

Collectively, these data show that weaning is followed by an upregulation of the GPx and GST activity in the small intestine. Piglets that undergo conventional weaning at either three or four weeks of age manage to maintain GSH redox homeostasis in the small intestinal throughout the weaning transition. In contrast, abrupt transfer from ad libitum milk replacer to a cereal-based weaner diet, does result in lower GSH stores throughout the weaning transition, and a GSH redox imbalance on d 5 post-weaning. In these piglets, this co-occurred with an overall defect in the barrier function, which was at its poorest at $\mathrm{d} 2$ to $\mathrm{d} 5$ post-weaning. The fact that massive changes in histo-morphology upon weaning did occur, whereas GSH redox homeostasis was maintained, suggests that the mucosal glutathione redox status does not correlate with small intestinal histo-morphology during the weaning transition.

\section{Supplementary information}

Supplementary information accompanies this paper at https://doi.org/10. 1186/s40104-020-00440-7.

Additional file $\mathbf{1}$ Table S1 Composition of the milk replacer and weaner diet, respectively used from $3 \mathrm{~d}$ of age until weaning and from d 0 to $\mathrm{d} 28$ post-weaning.

Additional file 2 Table S2 Overall effects of birht weight (BW), weaning treatment (WT) and days post-weaning (DPW) $(n=36-90)$. Table S3 The interaction effect of birht weight (BiW) and days post-weaning (DPW) ( $n=18$ ). Table S4 The interaction effect of weaning treatment (WT) and days post-weaning (DPW) $(n=12)$. Table S5 The interaction effect of birht weight (BiW) and weaning treatment (WT) $(n=30)$.

\section{Abbreviations}

$3 \mathrm{~d} 3 \mathrm{w}$ : Separated from the sow at $3 \mathrm{~d}$ of age and fed a milk replacer until weaning at 3 weeks of age; 3 w: Three weeks; 4 w: Four weeks; A: Exposed tissue surface area; ADFI: Average daily feed intake; ADG: Average daily gain; BCA: Bicinchoninic acid assay; Biw: Birth weight; $C_{0}$ : Initial concentration; dc/ $\mathrm{dt}$ : Change in concentration over time; DPW: Days post-weaning; FCR: Feed conversion ratio; FD4: Fluorescein isothiocyanate dextran; GPX: Glutathione peroxidase; GSH: Glutathione; GSH/GSSG E : Glutathione redox status; GSSG: Glutathione disulphide; GST: Glutathione-S-transferase; HRP: Horseradish peroxidase; IUGR: Intrauterine growth regarded; LBW: Low birth weight; MAPK: Mitogen-activated protein kinases;

MDA: Malondialdehyde; NBW: Normal birth weight; ORAC: Oxygen radical scavenging ability; $P_{\text {app: }}$ : Apparent permeability coefficient;

PCNA: Proliferating cell nuclear antigen; TPTs: Protein tyrosine phosphatases; $\mathrm{V}$ : volume; WT: Weaning treatment

\section{Acknowledgments}

We thank S. Coolsaet, E. Claeys, A. Ovyn, D. Baeyens, T. Van der Eecken, K. Huybrechts, G. Vrolix and K. Jennes for their skillful technical support, and P. Fransen from Volac (Volac International Ltd., Cambridge, UK) for providing the tailor-made milk replacer.

\section{Consent of publication}

All authors critically revised the manuscript for important intellectual contents and approved the final manuscript.

\section{Authors' contributions}

Author contributions: J.M., C.V.G. and S.D.S. concept and design of research; J.D., H.V., W.W., C.V.G. and J.M. performed experiments; J.D. and H.V. analyzed the data; J.D., S.D.S. and J.M. design and implementation of the statistical model; J.D., H.V., C.V.G., S.D.S. and J.M. interpreted the results of the experiments; J.D. and J.M. prepared the figures and drafted the manuscript; J.D., H.V., W.W., C.V.G., S.D.S., and J.M. edited and revised the manuscript and approved the final version of the manuscript.

\section{Funding}

This work was supported by a grant from the government agency for Innovation by Science and Technology (IWT-LO 100856).

\section{Availability of data and materials}

All analyzed data from this study are included in this published article and its supplementary information files.

\section{Ethics approval and consent to participate}

All husbandry and experimental procedures were approved by the Ethical Committees of Ghent University (Belgium) (EC number: 2011-195) and the University of Antwerp (Belgium) (EC number: 2015-02), and were in accordance with the European Commission directive for the humane care and use of animals in research (2010/63/EU).

\section{Competing interests}

The authors declare that they have no competing interests.

\section{Author details}

${ }^{1}$ Laboratory for Animal Nutrition and Animal Product Quality (LANUPRO),

Department of Animal Sciences and Aquatic Ecology, Faculty of Bioscience 
Engineering, Ghent University, Block F, Campus Coupure, Coupure Links 653, 9000 Ghent, Belgium. ${ }^{2}$ Laboratory of Applied Veterinary Morphology, Department of Veterinary Sciences, Faculty of Biomedical, Pharmaceutical and Veterinary Sciences, University of Antwerp, Universiteitsplein 1, Wilrijk, Belgium.

Received: 2 June 2019 Accepted: 24 February 2020

Published online: 23 April 2020

\section{References}

1. Colson V, Martin E, Orgeur P, Prunier A. Influence of housing and social changes on growth, behaviour and cortisol in piglets at weaning. Physiol Behav. 2012;107:59-64. https://doi.org/10.1016/j.physbeh.2012.06.001.

2. Stokes CR, Bailey M, Haverson $K$, Harris C, Jones P, Inman C, et al. Postnatal development of intestinal immune system in piglets: implications for the process of weaning. Anim Res. 2004;53:325-34. https://doi.org/10.1051/ animres:2004020.

3. Wijtten PJA, van der Meulen J, Verstegen MWA. Intestinal barrier function and absorption in pigs after weaning: a review. Br J Nutr. 2011;105:967-81. https://doi.org/10.1017/s0007114510005660.

4. Lallès JP, Boudry G, Favier C, Le Floc'H N, Luron IM, Montagne L, et al. Gut function and dysfunction in young pigs: physiology. Anim Res. 2004;53:30116. https://doi.org/10.1051/animres:2004018.

5. Dunshea F, Kerton DK, Cranwell PD, Campbell R, Mullan B. H king R et al. lifetime and post-weaning determinants of performance indices of pigs. Aust J Agric Res. 2003;54:363-70. https://doi.org/10.1071/AR02172.

6. van der Meulen J, Koopmans SJ, Dekker RA, Hoogendoorn A. Increasing weaning age of piglets from 4 to 7 weeks reduces stress, increases postweaning feed intake but does not improve intestinal functionality. Animal. 2010;4:1653-61. https://doi.org/10.1017/s1751731110001011.

7. Smith F, Clark JE, Overman BL, Tozel CC, Huang JH, Rivier JEF, et al. Early weaning stress impairs development of mucosal barrier function in the porcine intestine. Am J Physiol Gastrointest Liver Physiol. 2010;298:352-63. https://doi.org/10.1152/ajpgi.00081.2009.

8. Spreeuwenberg MAM, Verdonk JMAJ, Gaskins HR, Verstegen MWA. Smal intestine epithelial barrier function is compromised in pigs with low feed intake at weaning. J Nutr. 2001;131:1250-7. https://doi.org/10.1093/jn/131.5. 1520.

9. Zhao Y, Qin G, Sun Z, Che D, Bao N, Zhang X. Effects of soybean agglutinin on intestinal barrier permeability and tight junction protein expression in weaned piglets. Int J Mol Sci. 2011;12:8502-12. https://doi.org/10.3390/ ijms12128502.

10. Miller HM, Slade RD. Digestive physiology of the weaned pig. In: Pluske JR, Le Dividich J, MWA V, editors. Weaning the Pig: Concepts and Consequences. 1st ed. Wageningen, The Netherlands: Wageningen Academic Publishers; 2003. p. 117-39. https://doi.org/10.3920/978-908686-513-0

11. Jones DP, Sies H. The redox code. Antioxid Redox Signal. 2015;23:734-46. https://doi.org/10.1089/ars.2015.6247.

12. Rao RK, Basuroy S, Rao VU, Karnaky KJ Jr, Gupta A. Tyrosine phosphorylation and dissociation of occludin-ZO-1 and E-cadherin-beta-catenin complexes from the cytoskeleton by oxidative stress. Biochem J. 2002;368:471-81. https://doi.org/10.1042/bj20011804.

13. Rao R. Oxidative stress-induced disruption of epithelial and endothelial tight junctions. Front Biosci. 2008;13:7210-26. https://doi.org/10.2741/3223.

14. Rao RK, Li L, Baker RD, Baker SS, Gupta A. Glutathione oxidation and PTPase inhibition by hydrogen peroxide in Caco-2 cell monolayer. Am J Physiol Gastrointest Liver Physiol. 2000;279:332-40. https://doi.org/10.1152/ajpgi. 2000.279.2.G332.

15. Musch MW, Walsh-Reitz MM, Chang EB. Roles of ZO-1, occludin, and actin in oxidant-induced barrier disruption. Am J Physiol Gastrointest Liver Physiol. 2006;290:G222-31. https://doi.org/10.1152/ajpgi.00301.2005.

16. Jones DP. Redox sensing: orthogonal control in cell cycle and apoptosis signalling. J Intern Med. 2010;268:432-48. https://doi.org/10.1111/j.13652796.2010.02268.x

17. Circu ML, Aw TY. Intestinal redox biology and oxidative stress. Semin Cell Dev Biol. 2012;23:729-37. https://doi.org/10.1016/j.semcdb.2012.03.014

18. Schafer FQ, Buettner GR. Redox environment of the cell as viewed through the redox state of the glutathione disulfide/glutathione couple. Free Radic Biol Med. 2001;30:1191-212. https://doi.org/10.1016/S0891-5849(01)00480-4.
19. Degroote J, Michiels J, Claeys E, Ovyn A, De Smet S. Changes in the pig small intestinal mucosal glutathione kinetics after weaning. J Anim Sci. 2012;90:359-61. https://doi.org/10.2527/jas.53809.

20. Robert F, Bebin K, Garrau J-M, Gueriot J-F, Foret F, Brack B et al: Évaluation et correction du stress oxydatif du porcelet en post-sevrage. In: 41e journées de la recherche porcine: februari 3-4 2008; Paris, France. 2009: 173-178.

21. Li H, Wan HF, Mercier Y, Zhang XL, Wu CM, Wu XQ, et al. Changes in plasma amino acid profiles, growth performance and intestinal antioxidant capacity of piglets following increased consumption of methionine as its hydroxy analogue. Br J Nutr. 2014;112:855-67. https://doi.org/10.1017/ s000711451400172x.

22. Luo Z, Zhu W, Guo Q, Luo W, Zhang J, Xu W, et al. Weaning induced hepatic oxidative stress, apoptosis, and aminotransferases through MAPK signaling pathways in piglets. Oxidative Med Cell Longev. 2016;2016:1-10. https://doi.org/10.1155/2016/4768541.

23. Zhu L, Cai X, Guo Q, Chen X, Zhu S, Xu J. Effect of N-acetyl cysteine on enterocyte apoptosis and intracellular signalling pathways' response to oxidative stress in weaned piglets. Br J Nutr. 2013;110:1938-47. https://doi. org/10.1017/S0007114513001608

24. Xu CC, Yang SF, Zhu LH, Cai X, Sheng YS, Zhu SW, et al. Regulation of Nacetyl cysteine on gut redox status and major microbiota in weaned piglets. J Anim Sci. 2014;92:1504-11. https://doi.org/10.2527/jas.2013-6755.

25. Xu JX, Xu CC, Chen XL, Cai X, Yang SF, Sheng YS, et al. Regulation of an antioxidant blend on intestinal redox status and major microbiota in early weaned piglets. Nutrition. 2014;30:584-9. https://doi.org/10.1016/j.nut.2013.10.018.

26. Degroote J, Van Noten N, Wang W, De Smet S, Michiels J. Effects of nacetyl-cysteine supplementation through drinking water on the glutathione redox status during the weaning transition of piglets. Antioxidants. 2019;8: 24. https://doi.org/10.3390/antiox8010024

27. Wang J, Chen L, Li P, Li X, Zhou H, Wang F, et al. Gene expression is altered in piglet small intestine by weaning and dietary glutamine supplementation. J Nutr. 2008;138:1025-32. https:/doi.org/10.1093/jn/138.6.1025.

28. Michiels J, De Vos M, Missotten J, Ovyn A, De Smet S, Van Ginneken C. Maturation of digestive function is retarded and plasma antioxidant capacity lowered in fully weaned low birth weight piglets. Br J Nutr. 2013; 109:65-75. https://doi.org/10.1017/s0007114512000670.

29. Al Masri S, Hünigen H, Al Aiyan A, Rieger J, Zentek J, Richardson K, et al. Influence of age at weaning and feeding regimes on the postnatal morphology of the porcine small intestine: a review of morphometric studies. J Swine Health Prod. 2015;23:186-203. https://doi.org/10.13140/RG.2 1.1806 .5043$.

30. Wang W, Degroote J, Van Ginneken C, Van Poucke M, Vergauwen H, Dam $\mathrm{TM}$, et al. Intrauterine growth restriction in neonatal piglets affects small intestinal mucosal permeability and mRNA expression of redox-sensitive genes. FASEB J. 2016;30:863-73. https://doi.org/10.1096/fj.15-274779.

31. Vergauwen $H$, Degroote J, Prims S, Wang W, Fransen E, De Smet S, et al. Artificial rearing influences the morphology, permeability and redox state of the gastrointestinal tract of low and normal birth weight piglets. J Anim Sci Biotechnol. 2017;8:30. https://doi.org/10.1186/s40104-017-0159-3.

32. Zhang H, Li Y, Wang T. Antioxidant capacity and concentration of redoxactive trace mineral in fully weaned intra-uterine growth retardation piglets. J Anim Sci Biotechnol. 2015;6:48. https://doi.org/10.1186/s40104-015-0047-7.

33. Wang J, Chen L, Li D, Yin Y, Wang $X$, Li $P$, et al. Intrauterine growth restriction affects the proteomes of the small intestine, liver, and skeletal muscle in newborn pigs. J Nutr. 2008;138:60-6. https://doi.org/10.1093/jn/ 138.1.60.

34. Pluske JR, Hampson DJ, Williams $\uplus_{\text {. }}$. Factors influencing the structure and function of the small intestine in the weaned pig: a review. Livest Prod Sci. 1997;51:215-36. https://doi.org/10.1016/S0301-6226(97)00057-2.

35. De Vos M, Huygelen V, Willemen S, Fransen E, Casteleyn C, Van Cruchten S, et al. Artificial rearing of piglets: effects on small intestinal morphology and digestion capacity. Livest Sci. 2014;159:165-73. https://doi.org/10.1016/j. livsci.2013.11.012.

36. Ou B, Hampsch-Woodill M, Prior RL. Development and validation of an improved oxygen radical absorbance capacity assay using fluorescein as the fluorescent probe. J Agric Food Chem. 2001:49:4619-26. https://doi.org/10. 1021/jf0105860.

37. Grotto D, Santa Maria LD, Boeira S, Valentini J, Charão MF, Moro AM, et al. Rapid quantification of malondialdehyde in plasma by high performance liquid chromatography-visible detection. J Pharm Biomed Anal. 2007;43: 619-24. https://doi.org/10.1016/j.jpba.2006.07.030. 
38. Hernandez P, Zomeno L, Arino B, Blasco A. Antioxidant, lipolytic and proteolytic enzyme activities in pork meat from different genotypes. Meat Sci. 2004;66:525-9. https://doi.org/10.1016/s0309-1740(03)00155-4.

39. Habig WH, Jakoby WB. Assays for differentiation of glutathione Stransferases. Methods Enzymol. 1981;77:398-405. https://doi.org/10.1016/ S0076-6879(81)77053-8.

40. Reed DJ, Babson JR, Beatty PW, Brodie AE, Ellis WW, Potter DW. High performance liquid-chromatography analysis of nanomole levels of glutathione, glutathione disulfide and related thiols and disulfides. Anal Biochem. 1980;106:55-62. https://doi.org/10.1016/0003-2697(80)90118-9.

41. Yoshida T. Determination of reduced and oxidized glutathione in erythrocytes by high-performance liquid chromatography with ultraviolet absorbance detection. J Chromatogr B Biomed Appl. 1996;678:157-64. https://doi.org/10.1016/0378-4347(95)00489-0.

42. Neirinckx E, Vervaet C, Michiels J, De Smet S, Van den Broeck W, Remon JP, et al. Feasibility of the Ussing chamber technique for the determination of in vitro jejunal permeability of passively absorbed compounds in different animal species. J Vet Pharmacol Ther. 2011;34:290-7. https://doi.org/10. 1111/j.1365-2885.2010.01218.x.

43. McKie AT, Zammit PS, Naftalin RJ. Comparison of cattle and sheep colonic permeabilities to horseradish peroxidase and hamster scrapie prion protein in vitro. Gut. 1999;45:879-88. https://doi.org/10.1136/gut.45.6.879.

44. Degroote J, Wang W, Vergauwen H, De Smet S, Van Ginneken C, Michiels J. Impact of a dietary challenge with peroxidized oil on the glutathione redox status and integrity of the small intestine in weaned piglets. Animal. 2018: 1-10. https://doi.org/10.1017/S1751731118003166.

45. Guo Q, Cai X, Xu C, Luo Z, Sheng Y, Bao J, et al. Effects of dietary supplementation with $\mathrm{N}$-acetyl cysteine on antioxidant capacities and the expression of inflammatory cytokines in weaned piglets. Ital J Anim Sci. 2016:15:634-41. https://doi.org/10.1080/1828051X.2016.1222244.

46. Tao X, Xu Z, Men X. Transient effects of weaning on the health of newly weaning piglets. Czech J Anim Sci. 2016;61:82-90. https://doi.org/10.17221/ 8731-CJAS.

47. Buchet A, Belloc C, Leblanc-Maridor M, Merlot E. Effects of age and weaning conditions on blood indicators of oxidative status in pigs. PLoS One. 2017; 12:e0178487. https://doi.org/10.1371/journal.pone.0178487.

48. Sauerwein $H$, Schmitz S, Hiss S. Effects of a dietary application of a yeast cell wall extract on innate and acquired immunity, on oxidative status and growth performance in weanling piglets and on the ileal epithelium in fattened pigs. J Anim Physiol Anim Nutr. 2007;91:369-80. https://doi.org/10. 1111/j.1439-0396.2006.00663.x.

49. Samiec PS, Dahm $\sqcup$, Jones DP. Glutathione S-transferase in mucus of rat small intestine. Fundam Appl Toxicol. 2000:54:52-9. https://doi.org/10.1093/toxsci/54.1.52

50. Flohe L, Wingender E, Brigelius-Flohé R: The regulation of glutathione peroxidases. In: Oxidative stress and signalling transduction. Edited by Forman HJ, Cadenas E. University of Southern California: Springer Science+ Business Media; 1997: 415-440. https://doi.org/10.1007/978-1-4615-5981-8_17.

51. Couto N, Wood J, Barber J. The role of glutathione reductase and related enzymes on cellular redox homoeostasis network. Free Radic Biol Med. 2016:95:27-42. https://doi.org/10.1016/j.freeradbiomed.2016.02.028.

52. Ighodaro OM, Akinloye OA. First line defence antioxidants-superoxide dismutase (SOD), catalase (CAT) and glutathione peroxidase (GPX): their fundamental role in the entire antioxidant defence grid. Alexandria J Med. 2018;54:287-93. https://doi.org/10.1016/j.ajme.2017.09.001.

53. Lu SC. Glutathione synthesis. Biochim Biophys Acta Gen Subj. 1830;2013: 3143-53. https://doi.org/10.1016/j.bbagen.2012.09.008.

54. Aw TY. Cellular redox: a modulator of intestinal epithelial cell proliferation. News Physiol Sci. 2003;18:201-4. https://doi.org/10.1152/nips.01448.2003.

55. Boudry G, Peron V, Le Huerou-Luron I, Lalles JP, Seve B. Weaning induces both transient and long-lasting modifications of absorptive, secretory, and barrier properties of piglet intestine. J Nutr. 2004;134:2256-62. https://doi. org/10.1093/jn/134.9.2256.

56. Wang J, Zeng L, Tan B, Li G, Huang B, Xiong X, et al. Developmental changes in intercellular junctions and Kv channels in the intestine of piglets during the suckling and post-weaning periods. J Anim Sci Biotechnol. 2016; 7:4. https://doi.org/10.1186/s40104-016-0063-2.

57. Hedemann MS, Hojsgaard S, Jensen BB. Small intestinal morphology and activity of intestinal peptidases in piglets around weaning. J Anim Physiol Anim Nutr. 2003;87:32-41. https://doi.org/10.1046/j.1439-0396.2003.00405.x.

58. Niinikoski H, Stoll B, Guan X, Kansagra K, Lambert BD, Stephens J, et al. Onset of small intestinal atrophy is associated with reduced intestinal blood flow in TPN-fed neonatal piglets. J Nutr. 2004;134:1467-74. https://doi.org/ 10.1093/jn/134.6.1467.

59. Song Z, Tong G, Xiao K, Jiao Le F, Ke Y, Hu C. L-cysteine protects intestinal integrity, attenuates intestinal inflammation and oxidant stress, and modulates NF-kappaB and Nrf2 pathways in weaned piglets after LPS challenge. Innate Immun. 2016;22:152-61. https://doi.org/10.1177/ 1753425916632303.

60. Tian JQ, Washizawa N, Gu LH, Levin MS, Wang LH, Rubin DC, et al. Local glutathione redox status does not regulate ileal mucosal growth after massive small bowel resection in rats. J Nutr. 2007;137:320-5. https://doi. org/10.1093/jn/137.2.320.

61. Boudry G, Morise A, Seve B, Le Huerou-Luron I. Effect of milk formula protein content on intestinal barrier function in a porcine model of low birth weight neonates. Pediatr Res. 2011;69:4-9. https:/doi.org/10.1203/PDR.0b013e3181fc9d13.

62. Boudry G, Douard V, Mourot J, Lalles JP, Le Huerou-Luron I. Linseed oil in the maternal diet during gestation and lactation modifies fatty acid composition mucosal architecture, and mast cell regulation of the ileal barrier in piglets. J Nutr. 2009;139:1110-7. https://doi.org/10.3945/jn.108.102640.

63. Hu CH, Xiao K, Luan ZS, Song J. Early weaning increases intestinal permeability, alters expression of cytokine and tight junction proteins, and activates mitogen-activated protein kinases in pigs. J Anim Sci. 2013:91: 1094-101. https://doi.org/10.2527/jas.2012-5796.

64. González-Mariscal L, Tapia R, Chamorro D. Crosstalk of tight junction components with signaling pathways. Biochim Biophys Acta Biomembr. 1778;2008:729-56. https://doi.org/10.1016/j.bbamem.2007.08.018.

65. Turner JR. Intestinal mucosal barrier function in health and disease. Nat Rev Immunol. 2009;9:799-809. https://doi.org/10.1038/nri2653.

66. Milatz S, Krug SM, Rosenthal R, Günzel D, Müller D, Schulzke J-D, et al. Claudin-3 acts as a sealing component of the tight junction for ions of either charge and uncharged solutes. Biochim Biophys Acta Biomembr. 1798;2010:2048-57. https://doi.org/10.1016/j.bbamem.2010.07.014

67. Gitter AH, Bendfeldt K, Schulzke JD, Fromm M. Trans/paracellular, surface/ crypt, and epithelial/subepithelial resistances of mammalian colonic epithelia. Pflugers Arch. 2000;439:477-82. https://doi.org/10.1007/ s004249900202.

68. Collett A, Walker D, Sims E, He Y-L, Speers P, Ayrton J, et al. Influence of morphometric factors on quantitation of paracellular permeability of intestinal epithelia in vitro. Pharm Res. 1997;14:767-73. https://doi.org/10. 1023/A:1012154506858.

69. Humphries KM, Juliano C, Taylor SS. Regulation of CAMP-dependent protein kinase activity by glutathionylation. J Biol Chem. 2002;277:43505-11. https:// doi.org/10.1074/jbc.M207088200

70. Ward NE, Stewart JR, loannides CG, O'Brian CA. Oxidant-induced Sglutathiolation inactivates protein kinase C-alpha (PKC-alpha): a potential mechanism of PKC isozyme regulation. Biochemistry. 2000;39:10319-29. https://doi.org/10.1021/bi000781g.

71. Yun MR, Im DS, Lee SJ, Park HM, Bae SS, Lee WS, et al. 4-Hydroxynonenal enhances CD36 expression on murine macrophages via p38 MAPKmediated activation of 5-lipoxygenase. Free Radic Biol Med. 2009;46:692-8. https://doi.org/10.1016/j.freeradbiomed.2008.12.013.

72. Mahfoud R, Maresca M, Garmy N, Fantini J. The mycotoxin patulin alters the barrier function of the intestinal epithelium: mechanism of action of the toxin and protective effects of glutathione. Toxicol Appl Pharmacol. 2002; 181:209-18. https://doi.org/10.1006/taap.2002.9417.

73. Dominko K, Dikic D. Glutathionylation: a regulatory role of glutathione in physiological processes. Arh Hig Rada Toksikol. 2018;69:1-24. https://doi.org/ 10.2478/aiht-2018-69-2966

74. Pastore A, Piemonte F. S-Glutathionylation signaling in cell biology: Progress and prospects. Eur J Pharm Sci. 2012;46:279-92. https://doi.org/10.1016/j. ejps.2012.03.010

75. Brigelius-Flohe R, Flohe L. Basic principles and emerging concepts in the redox control of transcription factors. Antioxid Redox Signal. 2011;15:233581. https://doi.org/10.1089/ars.2010.3534.

76. Marcial MA, Carlson SL, Madara JL. Partitioning of paracellular conductance along the ileal crypt-villus axis: a hypothesis based on structural analysis with detailed consideration of tight junction structure-function relationships. J Membr Biol. 1984;80:59-70. https://doi. org/10.1007/bf01868690.

77. Madara J. Functional morphology of epithelium of the small intestine. In: Terjung R, editor. Handbook of physiology; 2011. p. 83-120. https://doi.org/ 10.1002/cphy.cp060403. 
78. Madara JL, Pappenheimer JR. Structural basis for physiological regulation of paracellular pathways in intestinal epithelia. J Membr Biol. 1987;100:149-64. https://doi.org/10.1007/bf02209147.

79. Odenwald MA, Turner JR. The intestinal epithelial barrier: a therapeutic target? Nat Rev Gastroenterol Hepatol. 2017;14:9-21. https://doi.org/10. 1038/nrgastro.2016.169.

80. Gardner MLG: A review of current knowledge of gastrointestinal absorption of intact proteins including medicinal preparations of proteolytic enzymes. In: Absorption of oral administered enzymes. Edited by Gardner MLG, Steffens KJ. Berlin, Heidelberg: Springer Berlin Heidelberg; 1995: 1-7. https:// doi.org/10.1007/978-3-642-79511-4_1.

81. Okamoto CT. Endocytosis and transcytosis. Adv Drug Deliv Rev. 1998;29: 215-28. https://doi.org/10.1016/s0169-409x(97)00080-x.

82. Pantzar N, Westrom BR, Luts A, Lundin S. Regional small-intestinal permeability in vitro to different-sized dextrans and proteins in the rat. Scand J Gastroenterol. 1993;28:205-11. https://doi.org/10.3109/ 00365529309096073

83. Matter K, Balda MS. Functional analysis of tight junctions. Methods. 2003;30: 228-34. https://doi.org/10.1016/S1046-2023(03)00029-X.

84. Gan L-SL, Thakker DR. Applications of the Caco-2 model in the design and development of orally active drugs: elucidation of biochemical and physical barriers posed by the intestinal epithelium. Adv Drug Deliv Rev. 1997:23:7798. https://doi.org/10.1016/S0169-409X(96)00427-9.

85. Sander GR, Cummins AG, Powell BC. Rapid disruption of intestinal barrie function by gliadin involves altered expression of apical junctional proteins. FEBS Lett. 2005;579:4851-5. https://doi.org/10.1016/j.febslet.2005.07.066.

Ready to submit your research? Choose BMC and benefit from:

- fast, convenient online submission

- thorough peer review by experienced researchers in your field

- rapid publication on acceptance

- support for research data, including large and complex data types

- gold Open Access which fosters wider collaboration and increased citations

- maximum visibility for your research: over $100 \mathrm{M}$ website views per year

At $\mathrm{BMC}$, research is always in progress.

Learn more biomedcentral.com/submissions 